aus. Sein Herz aber war nicht bloss weit, sondern auch warm. Wohl schloss es sich ganz nur denen, die ihm innerlich nahe standen, und auch ihnen nur in bewegter Stunde auf. Und solchen, denen norddeutsche Art in ihrer nordischsten Ausprägung fremd ist, konnte er bei flüchtigerer Berührung selbst kühl und ablehnend erscheinen. Doch wer jemals ihn erprobte, erfuhr die freundliche Güte seines Sinnes, die Weichheit seines Gemüthes, die Kraft seiner Liebe. So lebt er in unserem Gedächtniss fort, Erinnerung und Vorbild. Wenn aber die Tage kommen, da auch alle, die das Bild seines persönlichen Wesens in sich tragen, die Erde deckt, wird die Nachwelt noch die Frucht seines Wirkens geniessen und dankbar seiner treuen Arbeit für das deutsche Recht und den deutschen Staat gedenken.

\title{
II. \\ Die Aufhebung der Leibeigenschaft durch die Gesetzgebung Friedrichs des Grossen und das Allgemeine Preussische Landrecht.
}

\author{
Von \\ Herrn Professor Dr. Wilhelm v. Brünneck \\ in Halle a/S.
}

In der Geschichte der Gesetzgebung Friedrichs des Grossen, welche die Leibeigenschaft und ihre Aufhebung zum Gegenstande hat, tritt mit dem Jahre 1773 ein bedeutsamer Wendepunkt ein. War es bis dahin die Leibeigenschaft als ein Institut des deutschen Rechts gewesen, die den königlichen Gesetzgeber beschäftigt hatte, so galt es nach der Erwerbnng von Westpreussen und dem sog. Netzdistrict zu dem dort vorgefundenen polnischen Recht Stellung zu nehmen.

Will man die Friedericianische Reformgesetzgebung in Sachen der Leibeigenschaft richtig beurtheilen und würdigen, 
so bedarf vor anderen die Frage der Untersuchung und Beantwortung, ob und wie weit die Leibeigenschaft in den neu erworbenen slavischen Gebieten von dem gleichnamigen Institut in den übrigen preussischen Provinzen abwich.

Aber nicht allein der Gegensatz zwischen deutschem und slavischem Recht ist es, der die spätere preussische Gesetzgebung von der früheren aus der Zeit vor 1773 unterscheidet. Auch das Verfahren bei den Reformen, die an die Stelle des vorgefundenen älteren Rechts treten sollten, war ein anderes. Während die früheren Verordnungen des Königs über die Leibeigenschaft nicht ersehen lassen, dass sie nach irgend einem bestimmten Vorbilde gearbeitet sind, ist in der Gesetzgebung des Jahres 1773 ein Einfluss des Rechtes von Schlesien nicht $\mathrm{zu}$ verkennen.

Dieser Provinz liess der König in den Friedensjahren nach Beendigung des zweiten schlesischen Krieges seine besondere Fürsorge zu Theil werden. Der Inhalt der dort bis in das siebzehnte Jahrhundert zurückreichenden Verordnungen, welche die rechtliche Lage der unterthänigen Bauern verhältnissmässig günstig gestalteten, wurde nicht nur aufrecht erhalten, sondern genauer festgestellt und weiter entwickelt.

Eine Darstellung der Reformen Friedrichs des Grossen, die Leibeigenschaft betreffend, wird daher neben der Gesetzgebung des Jahres 1773, die ausser auf Westpreussen nebst den übrigen polnischen Erwerbungen sich zugleich auf Ostpreussen und Littauen erstreckt, auch das schlesische Provincialrecht in Betracht zu ziehen haben. Dieses hat nicht allein der Gesetzgebung des Jahres 1773 zum Vorbilde gedient. Es bildet auch, wie ich zu zeigen hoffe, zusammen mit der letzeren die Grundlage der Bestimmungen des Allgemeinen Preussischen Landrechts über Leibeigenschaft und Unterthänigkeit.

Der Schwerpunkt in der Geschichte der legislatorischen Massregeln, die eine Verbesserung der persönlichen Verhältnisse der unfreien Landbewohner anstrebten, fällt so in die neuere, mit 1773 beginnende Gesetzgebung. Von da ab nehmen die Reformen ihren Anfang, welche dahin abzielen, Grundsätze zu verallgemeinern, die bisher nur dem Rechte einer einzelnen Provinz und zwar Schlesiens angehört hatten. 
Immerhin erscheint es angezeigt, auch die frühere Gesetzgebung Friedrichs des Grossen, welche sich nicht auf Schlesien bezieht, mit zu berücksichtigen. Zwei Gründe sprechen hierfür. Einmal der, dass ihr ein namhafter Schriftsteller ${ }^{1}$ ) eine Bedeutung beigelegt hat, die ihr nicht zukommt. Ferner aber ist gerade der Gegensatz, in welchem die älteren legislativen Massregeln zu den späteren Reformen stehen, wohl geeignet, die letzteren in das rechte Licht za stellen und uns erkennen zu lassen, dass es sich dabei um keine bloss nominelle Abschaffung der Leibeigenschaft handelte.

I.

In die frühere Zeit der Gesetzgebung Friedrichs des Grossen fällt das von Samuel von Cocceji verfasste Project des corporis iuris Fridericiani. Seine ersten beiden Theile, die persönlichen und dinglichen Rechte enthaltend, erschienen 1749 und 1751. Bekanntlich hat dieses unvollendet gebliebene Gesetzeswerk, mit Ausnahme der die Ehe und Vormundschaftssachen behandelnden Abschnitte, niemals und nirgends Gesetzeskraft erlangt. So sind denn auch seine auf die Leibeigenschaft bezüglichen Vorschriften ohne praktische Bedeutung geblieben. Wohl aber sind sie von rechtshistorischem Interesse. Sie lassen uns den Standpunkt erkennen, welchen man bei dem ersten Versuche der Herstellung einer allgemeinen Gesetzgebung in Preussen zu der Frage der Leibeigenschaft einnahm. Das Project des corporis iuris Fridericiani vermeidet es, die Ausdrücke Leibeigenschaft und Leibeigene zu gebrauchen. Ebensowenig aber erklärt es etwa die Leibeigenschaft für aufgehoben. Als aufgehoben bezeichnet es nur die römische servitus. Diese mit dem Recht über Leben und Tod verknüpfte Knechtschaft widerstreite der Vollkommenheit des Christenthums. Wie in den meisten christlichen Staaten, sei sie daher auch in den Ländern der preussischen Monarchie abgeschafft. (P. I, L. I, Tit. V § 4.) Damit ist jedoch zufolge Coccejis weiterer Ausfiuhrung noch nicht jede Art von Knechtschaft überhaupt beseitigt. In einigen der preussischen Provinzen ist durch uralte Observanz eine andere Art der Knechtschaft und Dienstbarkeit eingeführt.

1) Koch, Lehrb. des preuss. gem. Privatr. I, S. 27. 
Zwar ändert sie nicht gleich der Sklaverei den status hominum, wohl aber afficirt sie die Person selbst und deren Condition auf gewisse Art (das. $\S 6$ ). Knechte von dieser Beschaffenheit sind die mit dem Namen der Eigenbehörigen oder Unterthanen (homines proprii, glebae adscripti) bezeichneten Leute.

Worin äussert sich nun aber ihre Knechtschaft? Diese Frage wird im $\S 7$ dahin beantwortet: „, so viel ibre Person anbetrifft", sind sie ,freye Leute, und können daher handeln und wandeln, und von ihren Actionen und Vermögen disponiren. Hingegen sind sie und ihre Kinder an gewisse der Herrschaft zugehörige Güter gebunden, welche sie bearbeiten, und ohne der Herrschaft Bewilligung nicht verlassen können; daher auch die Töchter sich auswärts nicht verheyrathen, sondern auf dem Hof oder in dem Gut bleiben und dienen müssen".

Man kann dexn entgegenhalten: Knechtschaft und Freiheit sind einander widersprechende Begriffe. Niemand vermag zu gleicher Zeit für seine Person frei und doch wiederum Knecht eines anderen zu sein. Auch die Thatsache, dass die im Project mit dem Namen der Eigenbehörigen oder Unterthanen bezeichneten Leute der Freizügigkeit ermangeln, kann für sich allein noch nicht die Behauptung rechtfertigen, dass ihr Zustand einer Knechtschaft gleichbedeutend sei ${ }^{1}$ ).

Ist dies aber nicht ein blosser Wortstreit? Kommt es im Resultat nicht auf dasselbe hinaus, ob man sagt: Jemand ist Knecht, weil er an die Scholle gebunden ist, während er im übrigen wie ein freier Mann handeln und wandeln kann, oder ob man dem glebae adscriptus die Freiheit beilegt, diese aber beschräukt sein lässt durch die rechtliche Beziehung, in welcher er zu dem Gute seines Herrn steht?

Nun, so völlig gleichgültig war dies um die Zeit, wo Cocceji sein Project verfasste, in Preussen doch nicht. Wie

1) Wer die Unfreiheit schon allein aus dem Mangel der Möglichkeit, sich frei von einem zu einem anderen Orte zu begeben, herleiten wollte, müsste folgerichtig den Kindern in väterlicher Gewalt und der Ehefrau ebenfalls die Freiheit absprechen. Ist es doch der Vater, beziehungsweise der Ehemann allein, der als das Haupt der Familie deren Wohnsitz zu bestimmen hat, wobin ihm Frau und Kinder folgen müssen. 
viel auch die Leibeigenschaft von ihrer alten Strenge im Laufe der Zeit verloren haben mochte, selbst damals war es, gegenüber den in den einzelnen Provinzen geltenden verschiedenen Rechten immer noch von Bedeutung, ob man für die rechtliche Beurtheilung und gesetzgeberische Behandlung des Zustandes der Leibeigenen den Ausgangspunkt von der Knechtschaft oder von der Freiheit nahm.

Das Project statuirte die Gebundenheit der eigenbehörigen Leute an gewisse der Herrschaft zugehörige Güter. Es blieb danach zweifelhaft, ob darunter einzelne bestimmte Güter oder nur Güter einer gewissen Kategorie, namentlich die Rittergüter $\mathrm{zu}$ verstehen waren. Im letzteren Falle würde die Gebundenbeit an die Scholle die Eigenbehörigen nicht davor bewahrt haben, dass sie nicht von ihren Herren an andere Gutsbesitzer veräussert würden, welche befugt waren, Unterthanen zu halten und herrschaftliche Rechte auszuüben. Die Gutsbehörigkeit würde sich dann nur darin wirksam zeigen, dass der Unterthan, weil er der Freizügigkeit ermangelte, sich von dem Gute, dem er zugeschlagen war, nicht losmachen durfte.

Anders wäre das Verhältniss zu denken, wenn der eigenbehörige und unterthänige Mann sich in rechtlicher Beziehung zu einem bestimmten einzelnen Gute befände. Dann wäre er nicht bloss verpflichtet, bei dem Gute des Herrn zu bleiben, er hätte auch seinerseits ein Recht darauf, dass die rechtliche Beziehung zwischen ihm und dem Gute und so mittelbar auch zu dessen Herrn nicht willkürlich gelöst und aufgehoben würde.

Von dieser Frwägung ausgehend wird man es nicht für gleichgültig halten, ob der Gesetzgeber die Eigenbehörigen als Knechte oder aber als freie, wenngleich in gewisser Hinsicht ihrer Rechtsfähigkeit nach beschränkte Leute betrachtet und behandelt wissen wollte.

Als freie Leute konnten sie dem Rechte ihrer Herren nur indirect unterworfen sein durch die Beziehung zu den Gütern, denen sie zugeschlagen waren. Das Eigenthumsrecht an letzteren gab den Herren erst mittelhar auch ein Recht über die glebae adscripti. Waren sie dagegen Knechte, dann bildeten sie für sich allein das Object eines den Herren gebührenden Rechts. Diese vermochten von ihrer Gewalt über sie Gebrauch zu machen, soweit ihnen das Gesetz darin nicht 
Schranken zog. Sie mussten daher auch für befugt erachtet werden, die Eigenbehörigen ohne die Güter, auf welchen sich diese seither befunden hatten, zu veräussern. Nur durfte solche Veräusserung nicht an beliebige Herren geschehen, sondern allein an die Besitzer von Gütern einer gewissen rechtlichen Qualität, insbesondere an die von Rittergütern.

Wenn daher das Project die Eigenbehörigen Knechte nennt und weiterhin den Herren ein dingliches Recht an ihnen zuschreibt ( $(9)$, ohne irgendwie anzudeuten, dass dies etwa nur Ausfluss sei des Eigenthums an den Gütern, denen sie zugeschlagen sind, so kann es meines Bedünkens nicht zweifelhaft sein, dass der Begrift der Eigenbehörigkeit hier absichtlich möglichst weit hat gefasst werden sollen. Cocceji wollte darunter nicht blos Leute verstanden wissen, die untrennbar mit einzelnen bestimmten Gütern verbunden waren. Er wollte darunter auch solche Unfreie begreifen, die von ihren Herren an andere veräussert werden durften, wenngleich nur mit der Massgabe, dass sie vom Zeitpunkt der stattgehabten Veräusserung $a b$ sofort wieder einem andern Gute einer gewissen Art, namentlich einem Rittergute zugeschlagen würden ${ }^{1}$ ).

So angesehen erscheint der Inhalt des Projects mit den zur Zeit seiner Entstehung geltenden Provincialrechten wohl vereinbar. Selbst das Recht Ostpreussens und Litthauens fand dabei noch seine Rechnung. Von inm habe ich an anderer Stelle ${ }^{2}$ ) nachgewiesen, dass es eine Veräusserung der Leibeigenen statuirte ohne die Güter, auf welchen sie sich befanden. Gerade die Rücksichtnahme auf das ostpreussische Recht, mit welchem er bei der Redaction des „Verbesserten Landrechts" Königs Friedrich Wilhelm I. von 1721 des näheren bekannt

1) Dem widerspricht auch nicht der $\S 8$ des Projects. Denn wenn da gesagt wird, sein Eigenthumsrecht erwerbe der Herr an den Eigenbehőrigen 1) durch Geburt und 2) ex pacto, ,wann sich ein freyer Mensch von freyen Stücken einer Herrschaft als eigenbehörig übergiebt", so ist offenbar nur an die Arten des Erwerbes gedacht, durch welche die Eigenbehörigkeit ũberhaupt erst entsteht. Es kann also daraus, dass der Möglichkeit, einen Eigenbehōrigen durch Ueberlassung von Seiten eines anderen Herrn zu erwerben, keine Erwähnung geschieht, nicht der Schluss gezogen werden, es habe eine solche Veräusserung nach Coccejis Meinung überhaupt nicht stattfinden können. 2) S. J. G. VIII dieser Zeitschrift G. A. S. 57. 
geworden war ${ }^{1}$ ), mag Cocceji veranlasst haben, den auf die Eigenbehörigen bezüglichen Vorschriften des Projects eine möglichst weite und vage Fassung zu geben. Nur so war es möglich, darunter auch solche Rechte der Grundherren zu begreifen, welche ihnen unmittelbar gegen die Person der Eigenbehörigen und nicht blos vermöge des Eigenthums ihrer Güter zustanden. Ueberhaupt aber ist hier der Umstand zu beachten, dass das Project des corporis iuris Fridericiani, obwohl es sich sonst gegen das provincielle Recht im allgemeinen ziemlich spröde verhält ${ }^{2}$ ), die über die Leibeigenschaft in den verschiedenen einzelnen Provinzen bestehenden Gesetze und Gewohnheiten durchaus schonend behandelt ${ }^{3}$ ). Cocceji hat augenscheinlich vermeiden wollen, irgend etwas darin festzusetzen, was in Widerspruch treten möchte mit den in den Provincialrechten den Herren über ihre Leibeigenen beziehungsweise gutsbehörigen Leute eingeräumten Rechten.

Es darf uns so denn auch nicht Wunder nehmen, dass das Project nirgends die Frage aufwirft, noch zu beantworten sucht, ob und unter welchen Voraussetzungen die Eigenbehörigen ohne Willen und Zuthun ihrer Herren der Eigenbehörigkeit ledig werden und zur Freiheit gelangen können.

Der Tod Coccejis und der bald danach ausbrechende siebenjährige Krieg machte den Codificationsarbeiten ein Ende. Die Leibeigenschaft hörte damit auf, ein Gegenstand der allgemeinen Gesetzgebung zu sein. Die legislatorische Thätigkeit war zunächst allein auf die Rechte der einzelnen Provinzen angewiesen, wenn sie sich mit dem Institut der Leibeigenschaft befasste, um dasselbe neu zu gestalten oder womöglich gänzlich abzuschaffen.

Die erste Provinz, in welcher Friedrich der Grosse eine förmliche Aufhebung der Leibeigenschaft ins Auge fasste, war Pommern. Noch während der Dauer des siebenjährigen Krieges

1) S. das Publicationspatent des Verbess. L.-R. von 1721 und dazu den von Stintzing verfassten Artikel: Samuel v. Cocceji in der Allgem. deutschen Biographie IV, S. 373 ff. - 2) Vgl. P. I, Lib. I, Tit. II, \$ 15. - - ) Der $\$ 12$ sagt ausdrücklich: „Weil in jeder Provinz, wo dergleichen Eigenbehörige vorhanden sind, ein besonderes Eigenthumsrecht statuirt worden, so wollen Wir Uns dahin beziehen, und müssen Unsere Justitz-Collegia alle vorkommende Sachen darnach entscheiden." 
sprach der König in einer von Breslau den 20. April 1762 datirten Instruction ${ }^{1}$ ) für den Geheimen Finanzrath von Brenkenhoff es als seine „expresse Willensmeinung“ aus: „Da die überall schädliche Leibeigenschaft derer Untertanen in Pommern und die ungemessenen Dienste, so dieselben verrichten müssen, den dasigen Lande allezeit verderblich gewesen, so dass die Provinz deshalb nie zur rechter Aufnahme kommen können - die Leibeigenschaft der dasigen Untertanen ibberall gäntzlich aufgehoben und abgeschaffet werden soll".

Soweit es die Amtsunterthanen auf den Domänen anging, sollte die Leibeigenschaft sogleich aufgehoben und die ungemessenen Dienste so regulirt werden, dass diese ihre Wirthschaften füglich dabei verrichten könnten.

Den adeligen Grundherren aber liess der König eröffnen : der oder diejenigen von ihnen, welche sich dagegen setzen und die Leibeigenschaft auf ihren Gütern nicht abschaffen würden, sollten weder jetzt, mit Rücksicht auf die in Zeiten des Krieges durch die Russen stattgehabte Verwüstung mancher Kreise von Hinterpommern, noch jemals einige Hülfe vom Staate bekommen, noch zu gewärtigen haben, während sie dessenungeachtet angehalten werden würden, ihre Güter zu retablireu und mit der gehörigen Anzahl Unterthanen wieder zu besetzen.

Noch kategorischer lautete die Weisung, welche Friedrich II., als er im folgenden Jahre, nach dem inzwischen abgeschlossenen Hubertsburger Frieden, Hinterpommern besuchte, demselben Beamten zu Colberg am 23. Mai 1763 mündlich ertheilte ${ }^{2}$ ): „Sollen absolut, und ohne das geringste Raisonniren, alle Leibeigenschaft, sowohl in Königlichen, Adlichen, als Stadteigenthums Dörfern, von Stund an gänzlich abgeschafit werden, und alle diejenigen, so sich dagegen opponiren würden, so viel möglich mit Güte, in deren Entstehung aber mit Force dahin gebracht werden, dass diese von Sr. Königl. Majestät so festgesetzte Idee zum Nutzen der ganzen Provinz ins Werk gerichtet werde."

1) S. Stadelmann, Preussens Könige in ihrer Thätigkeit für die Landescultur II, Urkunde nr. 148, S. $336 \mathrm{ff}$. - 2) S. Extract aus einer vom König dem Geh. Finanzrath v, Brenckenhoff ertheilten mündlichen Instruction bei Stadelmann a. a. O. S. 340, nr. 154. 
Infolge des so wiederholt von höchster Stelle aus ertheilten Befehls, dessen stricte Befolgung eine C.-O. vom 7. Juli 1763 einschärfte ${ }^{1}$ ), wurde den Landständen von Vorund Hinterpommern durch die pommersche Kriegs- und Domänenkammer zu Stettin am 28. Juni 1763 aufgegeben, sich schleunigst $\mathrm{zu}$ versammeln und ungesäumt Vorschläge zu thun, welchergestalt die Willensmeinung des Königs, betreffend die Aufhebung der Leibeigenschaft, am leichtesten in Ausführung zu bringen sei.

Bei den hierauf stattfindenden Verhandlungen mit den pommerschen Ständen musste es für die beabsichtigte Reform verhängnissvoll werden, dass Friedrich der Grosse sich darauf beschränkt hatte, die Abschaffung der Leibeigenschaft in ganz allgemein gefassten Worten auszusprechen.

Anders wie in den Edicte seines Vaters uud Vorgängers Friedrich Wilhelm I. vom 22. März 1719, betreffend die Aufhebung der Leibeigenschaft in den hinterpommerschen und camminschen Aemtern, mangelte es an jeder näheren Definition, was unter Leibeigenschaft verstanden und in welcher Weise das in ihr begründete Abhängigkeitsverhältniss zwischen den Grundherren und ihren unterthänigen Bauern gelöst werden sollte. Die Stände unterliessen es denn auch nicht, diesen Umstand in ihrem Interesse zu benutzen. Indem sie an den Zweifel anknüpften, den der Wortlaut des königlichen Befehls bezüglich des Begriffes der Leibeigenschaft offen liess, suchten sie von vornherein der verfügten Massregel ihre Schärfe zu benehmen und ihre Bedeutung abzuschwächen.

Die von den vorpommerschen Ständen zu Demmin am 29. Juni 1763 beschlossene ,Vorstellung und Erklärung wegen der von Sr. Königl. Majestät Allerhöchst befohlenen Aufhebung der Leibeigenschaft" 2) geht von der Annahme aus, als stelle sich der König unter der Leibeigenschaft einen Zustand völliger Rechtlosigkeit und Sklaverei vor. Eine Leibeigenschaft in diesem Sinne, vermöge welcher der Bauer mit Leib und Gut im Eigenthum des Adels gewesen, so dass er über nichts $\mathrm{zu}$ disponiren gehabt, sondern alles, was er habe erwerben

1) S. Stadelmann a. a. O. S. 340. 341, nr. 155. - 2) Sie findet sich abgedruckt in Balthasar, Tractat. de hom. propr. in Pom. p. 351-356. 
können, zum Gebote seines Herrn gestanden, und er nicht nur $\mathrm{zu}$ allen Diensten ohne Unterschied verbunden gewesen sei, sondern auch der Herr mit ihm habe Handel treiben, ihn verschenken, vertauschen und verkaufen dürfen, sei in den ältesten Zeiten, wie unter den Slawen und Wenden überhaupt, so auch in Pommern vorhanden gewesen. Nachdem aber die Slawen und Wenden das Land zum grössten Theil verlassen, so habe sich auch die Leibeigenschaft in ihrer ursprünglichen Bedeutung verloren. Diese werde jetzt in Vorpommern ,in keinem audern Verstande genommen, als nur in dem einer Gutspflichtigkeit". Letztere habe mit der eigentlichen Leibeigenschaft nichts gemein. Denn der Bauer habe über das Seinige frei zu verfügen; was er erwerbe, gehöre ihm, er könne damit thun und lassen, was er wolle, ohne dass der Herr darauf einigen Anspruch habe. In seiner persönlichen Freiheit werde derselbe dadurch nur insoweit eingeschränkt, dass er für sich und seine Nachkommen verbunden sei, innerhalb des herrschaftlichen Gutes auf dem ihm eingegebenen Hofe, von dem er statt der Pacht Dienste leiste, zu bleiben und ohne die Einwilligung des Grundherrn nicht wegzuziehen, noch aus dem Gute zu weichen.

Sehen wir einmal von der Behauptung ab, die sich historisch nicht rechtfertigen lässt ${ }^{1}$ ), dass die Leibeigenschaft in slawischer Zeit einer Sklaverei gleichkam. Im übrigen war das Rechtsverhältniss der leibeigenen Bauern in Pommern, wie sich dasselbe theils schon im Mittelalter, in allgemeiner Verbreitung aber seit dem sechzehnten Jahrhundert entwickelt hatte und in der Bauernordnung von 1616 die gesetzliche Anerkennung gefunden hatte, in dieser Vorstellung der vorpommerschen Stände richtig dargestellt. Gleich der neueren deutschen Leibeigenschaft involvirte auch die Leibeigenschaft Pommerns wohl eine Einschränkung der persönlichen Freiheit nach gewissen Richtungen hin, nicht aber hob sie diese etwa völlig auf.

Nicht ohne Grund durften daher die vorpommerschen Stände bei den Verhandlungen ${ }^{2}$ ) über die königliche Propo-

1) S. meine Abhandlung in dieser Zeitschrift J.-G. IX, G. A. S. 113-115. - 2) S. hierüber Balthasar a. a. 0. p. 351. 
sition und in der im Gefolge derselben beschlossenen Vorstellung selbst darauf hinweisen, dass, wenn der König eben nur die Abschaffung der Leibeigenschaft als einer Art von Sklaverei verlange, eine solche in Pommern überhaupt nicht mehr vorhanden sei. Es könne sich also bloss darum handeln, dem, was ohnehin schon Rechtens im Lande sei, den genaueren und deutlicheren gesetzlichen Ausdruck zu geben. Sie erklärten sich denn auch gern zufrieden, dass, sofern nur die Gutspflichtigkeit erhalten bleibe, durch ein neueres Gesetz die Abschaffung der Leibeigenschaft förmlich ausgesprochen werde, so dass dem Gutsherrn aus dem Grunde derselben niemals ein Recht an des Bauern Person und Vermögen zustehe, sondern der Bauer über alles, was er erwerbe, ausser der Hofwehr und was ihm von der Herrschaft vorschussweise gegeben, frei zu verfügen habe.

Wurde auf diese Weise dem König der Gedanke und die Absicht untergeschoben, dass er bei der geplanten Reform allein die Abschaffiung der Leibeigenschaft als einer Art persönlicher Sklaverei bezweckte, so war es den vorpommerschen Ständen leicht, die Bedenken geltend zu machen, welche einer gänzlichen Auflösung der Verbindung zwischen den Grundherren und ihren Bauern entgegenstanden, wenn man etwa damit umgehen sollte, zugleich auch die Gutspflichtigkeit oder Grundbehörigkeit aufzuheben. Indem sie die hierauf zu erstreckende Reform als eine bloss abstracte Möglichkeit hinstellten, welche selbst nicht Gegenstand der königlichen Willensmeinung sei, begegneten sie bei Anführung ihrer Gegengründe dem Vorwurfe, dass sie principielle Widersacher des königlichen Planes seien. Mit der Aufhebung der Gutspflichtigkeit, so führten sie in der schon gedachten Vorstellung aus, würde, entgegen der Intention des Königs, welche auf die Steigerung der Volkszahl gehe, eine Entvölkerung der Provinz eintreten. Die auf die herrschaftlichen Höfe angesetzten Bauern würden, sobald sie aufhörten, an die Scholle gebunden zu sein, an welcher sie nichts Eigenes besässen, nach fruchtbareren Gegenden, namentlich nach dem angrenzenden Schwedisch-Vorpommern iund Mecklenburg auswandern. Es werde so, in Ermangelung von Arbeitskräften, ein Rückgang der Landwirthschaft und dadurch eine allgemeine 
Theuerung entstehen. Auch sei die in der Gutspflichtigkeit beruhende Verbindung zwischen den Bauern und Gutsherren bisher das Mittel gewesen, so manche Bauern im Lande zu erhalten, welche sonst aus Furcht vor der Werbung und ihrer Einstellung als Soldaten in die Armee hätten flüchtig werden und austreten wollen. Lasse doch bei dem jetzt bestehenden Verhältniss ein jeder Gutsherr es sich angelegen sein, seine gutspflichtigen Leute an anderen Orten zu reclamiren, wenn diese sich ohne seine Bewilligung aus dem Bereiche seiner Herrschaft entfernten.

Entsprechende Deductionen enthielt die Denkschrift der hinterpommerschen Stände ${ }^{1}$ ). Auch sie erklärten sich damit einverstanden, dass die Abschaffung der Leibeigenschaft durch ein neues Gesetz förmlich constatirt und ausgesprochen werde. Sie verlangten nur die Beibehaltung der Gutspflichtigkeit, die sie als Erbunterthänigkeit, oder wie das neue Landrecht ${ }^{2}$ ) es nenne, als Eigenbehörigkeit bezeichnet wissen wollten. Sie stellten deshalb anheim, in einer neuen Bauernordnung diese Benennung statt der der Leibeigenschaft zu gebrauchen.

Aber nicht allein von den Ständen der Provinz sondern auch aus der Mitte der Beamtenschaft gingen dem Könige Vorstellungen $\mathrm{zu}$, welche darauf berechnet waren, der geplanten Reform ihren radicalen Charakter zu nehmen. Brenckenhoff selbst schrieb $^{3}$ ), es werde in Pommern vorausgesetzt: „dass die Meinung des Königs nicht auf eine unbeschränkte Freiheit der Unterthanen, als des Extrems von der Leibeigenschaft abziele, sondern wohl auf die Mittelstrasse zwischen beiden".

Noch unumwundener aber sprach sich die pommersche Kriegs- und Domänenkammer für die Stände und den von diesen eingenommenen Standpunkt aus. Obgleich, so führt ein Bericht" ${ }^{4}$ ) dieser Behörde an 'den König resp. an das Generaldirectorium vom 28. September 1763 aus, laut Inhalt

1) S. über den Inhalt dieses bis jetzt noch nicht gedruckten Schriftstūckes Stadelmann a. a. O. II, S. 104. 105, womit jetzt noch verglichen werden mag, was Knapp, Die Bauernbefreiung u. s. w. II, S. 55 beibringt. - 2) Damit war das corpus iur. Frid. gemeint. - 's) Stadelmann a. a. O. S. 105. - 4) Stadelmann a. a. O. S. 105. S. auch Knapp, Bauernbefreiung II, S. 56. 
der Bauernordnungen von 1616 und 1670 den Gutsherrschaften das Recht der Leibeigenschaft über ihre angeborenen Unterthanen zustehe, seien doch die Landstände bereit, trotz dieser Gerechtsame ihren Unterthanen die Stellung als Erbunterthanen oder Eigenbehörige zu gewähren. Würden die Leute völlig frei, so müsse man befürchten, dass sie nach anderen fruchtbareren Gegenden auswanderten. Pommern werde dann bald ohne Landarbeiter sein. Ganz besonders wird noch ausserdem auf die Gefahr hingewiesen, die für das Cantonwesen aus der Aufhebung der Gutspflichtigkeit entstehen möchte. Denn mit dem Aufhören derselben werde die "Desertion von Militär" bei den Bauern sehr erheblich zunelımen.

Diese Vorstellungen mit den darin enthaltenen Bedenken verfehlten ihren Eindruck nicht. Friedrich der Grosse sah sich bewogen, die von ihm getroffene Anordnung in ihrer Schärfe abzuschwächen. Durch C.-O. vom 13. November 1763 beauftragte er die pommersche Kriegs- und Domänenkammer, in Gemeinschaft mit den Landständen eine Revision der Bauer-, Schäfer- und Gesindeordnung zu entwerfen und ihm vorzulegen. Es entstand so die „Bauernordnung vor das Herzogthum Vorund Hinterpommern" vom 30. December 1764 ${ }^{1}$ ), welche die königliche Confirmation erhielt.

Mit Bezug auf die uns hier allein interessirende Frage nach dem rechtlichen Zustande der Bauern in persönlicher Hinsicht wird in ihrem Titel III, \& 1 Folgendes bestimmt:

"Obgleich die Bauern in Pommern keine leibeignen Sklaven sind, die da verschenckt, verkauft oder als res in commercio tracktiret werden könten, und sie deshalb auch was sie durch ihren Fleiss und Arbeit, ausser der ihnen von der Herrschaft gegebenen Hofwehr erwerben, als ihr Eigenthum besitzen, darüber frey disponiren können, und auf ihre Kinder vererben, so ist doch dagegen auch ausser Streit, dass Acker, Wiesen, Gärten und Häuser, welche sie besitzen, wo nicht in einigen Dörfern ein anderes durch Kauf-Contract, oder sonst ausdrücklich vestgesetzt ist, der Herrschaft des Gutes als res soli eigenthümlich gehören, und sie von selbiger ausserdem

1) S. diese in der sog. academischen Edictensammlung des N. C. G. Thl. III, S. $532 \mathrm{ff}$. 
die Hofwehr empfangen haben; sie selbsten aber keine Erbzins- oder Pacht-Leute, sondern des Guths-Eigenbehörige Unterthanen und glebae adscripti sind, und von denen Höfen, Aeckern und Wiesen, welche ihnen einmahl eingegeben, nur geringe jährige Pacht entrichten, dagegen aber allerhand Dienste, so wie solche zu Bestellung des Guths nöthig, und an jedem Orte hergebracht sind, leisten müssen, auch sie und ihre Kinder nicht befugt sind, ohne Vorwissen und Einwilligung der Guths-Herrschaft aus dem Guthe sich weg zu begeben."

Vergleicht man diese Bestimmungen der neuen Bauernordnung mit den entsprechenden Vorschriften der älteren Bauernordnung von 1616 Tit. 11, nr. 11, so sind es im wesentlichen bloss formale Aenderungen, wodurch sich das jüngere von dem älteren Gesetz unterscheidet.

Während die Bauern nach wie vor die Eigenschaft von glebae adscripti behalten, wird der früher gebrauchte Ausdruck Leibeigenschaft mit dem der Eigenbehörigkeit vertauscht. Wenn ferner die neue Bauernordnung ausdrücklich constatirte, die Bauern in Pommern seien keine leibeigenen Sklaven, die ohne das Gut, dem sie zugehören, beliebig verschenkt oder verkauft werden könnten, so war auch in dem hierüber Gesagten nichts Neues enthalten. Es ward damit nur förmlich ausgesprochen, was ohnehin schon im Lande Rechtens war und sich aus dem Inhalte der älteren Gesetzgebung bei richtiger Auslegung ergab ${ }^{1}$ ).

Die einzige sachliche Aenderung betraf die Regelung der von den gutsbehörigen Bauern zu leistenden Frohnden. War die Verpflichtung hierzu ehedem eine völlig ungewisse und unbemessene gewesen, so sollte sich ihr Umfang jetzt nach dem wirthschaftlichen Bedürfniss der Güter und nach dem örtlichen Herkommen richten. In dieser einen Beziehung erfuhr das Recht der Herren eine gewisse Einschränkung. Sonst verloren diese nichts an ihren Rechten gegen die gutspflichtigen Bauern. Von einem Verzicht auf irgend erhebliche oder wesentliche Gerechtsame an der Person der Bauern, zu

1) S. meine Abhandlung in dieser Zeitschrift J. G. IX, G. A., S. 141-143 und vgl. damit den Inhalt der Vorstellung der vorpommerschen Stände oben S. 32 . 33 . 
dem sich nach dem vorhin erwähnten Bericht der pommerschen Kriegs- und Domänenkammer die Gutsherren bereit erklärten, wenn sie in die Umwandelung der Leibeigenschaft in die Eigenbehörigkeit oder Erbunterthänigkeit willigten, konnte füglich nicht die Rede sein. Uebrigens ist dies nicht bloss mit Rücksicht auf die oben angeführten Bestimmungen der neuen Bauernordnung zu behaupten. Auch ihr sonstiger Inhalt, soweit er hier einschlägt, stimmt durchaus mit dem der älteren pommerschen Gesetzgebung überein. Bemerkt sei da namentlich, dass, gleich der älteren von 1616, die neuere Bauernordnung von 1764 die Verbindung der gutspflichtigen Bauern mit ihren Herren als eine der Regel nach unauflösliche behandelt. Ein Recht, die Entlassung aus der Gutsbehörigkeit zu fordern, sei es unentgeltlich, sei es gegen Entrichtung eines Loskaufgeldes, steht den Unterthanen gegen ihre Herren ebensowenig zu wie früher. Der einzige Fall, wo der Bauer wider den Willen des Herrn nebst Weib und Kindern für frei erklärt werden soll, bleibt der, wenn der Herr ihn ohne rechtmässige Ursache, und ohne ihm eine andere Stelle innerhalb seiner Grundherrschaft anzuweisen, des Hofes entsetzt, auf dem er bis dahin gewohnt hat ${ }^{1}$ ).

Es muss daher als eine irrige Meinung bezeichnet werden, wenn Koch ${ }^{2}$ ) die Bedeutung der durch die Bauernordnung von 1764 vorgenommenen Umwandlung der Leibeigenschaft in die Gutsbehörigkeit darin finden will, dass den unterthänigen Bauern eine Lösung ihres Verhältnisses zu den Grundherren freistehen sollte. Die Statuirung der Möglichkeit einer solchen Lösung durch die preussische Gesetzgebung hat ihren Ursprung nicht im Rechte Pommerns; sie geht, wie wir weiterhin sehen werden, vom Rechte Schlesiens aus.

Nicht mit der Bauernordnung von 1616, wohl aber mit der späteren Gesetzgebung Pommerns und zwar Vorpommerns kommen die Vorschriften überein, welche die neue Bauernordnung von 1764 über die Verlöbnisse der gutsbehörigen Unterthanen in ihrem Tit. II aufstellte. Man entlehnte die-

1) S. Bauernordnung 1764 Tit.sIl, § 11 vgl. mit Bauernordnung 1616 Tit. XI, nr. 16 und dazu meine Abhandlung in dieser Zeitschrift IX, G. A. S. 143. 144. 147-148. - ${ }^{2}$ ) S. dessen Lehrbuch des preussischen gemeinen Privatrechts (dritte Aufl.) I, S. 27. 
selben der in Vorpommern unter der Regierung des schwedischen Königs Karl XI. eingeführten Gesinde-, Bauer- und Schäferordnung vom 7. Januar 1670. Jenes Gesetz hatte in Altvorpommern seine Geltung auch dann noch behalten, nachdem dieser Theil Vorpommerns infolge des nordischen Krieges im Jahre 1720 mit Brandenburg-Preussen vereinigt worden war $\left.{ }^{1}\right)$.

Sachliche Aenderungen wurden dabei nicht vorgenommen. Eine Veranlassung dazu lag nicht vor. Konnte doch die von den gutsbehörigen Bauern bei ihren Grundherren einzuholende Einwilligung zu Verlöbnissen nicht als Ausfluss eines Rechtes an der Person der Unterthanen selbst und an und für sich gelten ${ }^{2}$ ). Sie ergab sich erst als die mittelbare Folge aus ihrem Verhältniss zu den Gütern, welchen sie zugeschlagen waren und für deren Besitzer sie zu zinsen und zu frohnden batten.

Man konnte sich daher hier ebenso wie bei den auf die Umwandelung der Leibeigenschaft in die Eigenbehörigkeit bezüglichen Vorschriften auf rein formale Aenderungen beschränken. Was diese anbelangt, so mag hier noch erwähnt sein, dass an Stelle des in der Schwedischen Ordnung von 1670 genannten Consistoriums nach der Bauernordnung von 1764 das zuständige Justizcollegium als diejenige Behörde treten sollte, bei welcher fortan die Grundherren auf Ungültigkeitserklärung der ohne ihre Zustimmung geschlossenen Verlöbnisse der gutsbehörigen Unterthanen Klage zu erheben hatten ${ }^{3}$ ). Es hing dies zusammen mit der 1748 im ganzen damaligen Umfange des preussischen Staates erfolgten Aufhebung der Gerichtsbarkeit der Consistorien, namentlich in Ehe- und Verlöbnisssachen, unter Ueberweisung derselben an die weltlichen Gerichte ${ }^{4}$ ).

Nach alledem wird man der Abschaffung der Leibeigenschaft in Pommern durch die Bauernordnung von 1764 eine praktische Bedeutung für das Recht dieser Provinz nicht beizumessen haben. Es war in der That eine bloss nominelle,

1) S. meine Abhandlung in dieser Zeitschrift IX, G. A., S. 149. $\left.{ }^{2}\right)$ S. das. S. 151. 152. - $\left.{ }^{3}\right)$ S. das. a. a. O. S. 150. - 4) S. RichterDove-Kahle, Kirchenrecht S. 513, Note 6 und Forster-Eccius, Theorie und Praxis des preuss. Privatr. (4. Aufl.) IV, S. 10. 
rein formale Aenderung, wenn man die Bezeichnung Leibeigenschaft mit der der Eigenbehörigkeit vertauschte, während man es in allen wesentlichen Punkten bezüglich der Rechtsverhältnisse der Bauern als gutsbehöriger oder gutspflichtiger Leute beim Alten liess.

Anders freilich muss unser Urtheil über dieses Gesetz lauten, wenn wir es nicht im Zusammenhange mit dem besonderen Rechte Pommerns betrachten, sondern seine Stellung innerhalb des weiteren Rahmens der Geschichte der preussischen Gesetzgebung überhaupt in Erwägung ziehen. Da war es immerhin nicht unwichtig, vielmehr als ein Fortschritt auf dem Wege zu einer völligen Emancipation der Bauern zu begrüssen, dass einmal klar und deutlich vom Gesetzgeber ausgesprochen wurde, die gutsbehörigen Leute seien keine leibeigenen Sklaven. Sie könnten für sich allein nicht veräussert, noch sonstwie als res in commercio behandelt werden. Liess doch noch das Project des corporis iuris Fridericiani, indem es die Eigenbehörigen als Knechte bezeichnete, die Frage offen, ob es den Grundherren gestattet blieb, ihre Leute ohne die Güter zu veräussern.

Nicht anders wie mit der Leibeigenschaft in Pommern und ihrer Aufhebung durch Friedrich den Grossen verhält es sich mit der Leibeigenschaft der Ucker- und Neumark. Nur diese Theile der Mark Brandenburg kommen hier uiberhaupt in Betracht. Im ganzen übrigen Gebietsumfange dieser Provinz sind die Bauern von der Zeit des Mittelalters an immer persönlich freie Leute gewesen und geblieben ${ }^{1}$ ). Eine Leibeigenschaft hat da niemals stattgehabt, weder im Sinne einer Art von Sklaverei, noch in der Bedeutung der blossen Gutsbehörigkeit. Zwar wurden die märkischen Bauern seit dem sechzehnten Jahrhundert genöthigt, bei beabsichtigtem Domicilwechsel ihren

1) S. Korn, Geschichte der bäuerlichen Rechtsverhältnisse in der Mark Brandenburg in der Zeitschrift für R.-G. XI, S. 1-44. So wenig wie in der Mark Brandenburg, wenn wir absehen von der Ucker- und Neumark, bestand im vorigen Jahrhundert eine persőnliche Unfreiheit der Bauern in den seit 1648 an Brandenburg gekommenen sächsischen Gebieten von Magdeburg, Halberstadt.u. s. w. S. hierüber L. Krug, Ueber Leibeigenschaft u. s. w. in den preussischen Staaten (Halle, 1798) S. 65 . 
Grundherren andere taugliche Wirthe zu stellen, um als sog. Gewährsmänner an ihrer Statt die Bewirthschaftung der von ihnen verlassenen Höfe mit der darauf ruhenden Zins- und Frohnpflicht $\mathrm{zu}$ übernehmen ${ }^{1}$ ). Ihre Freizügigkeit selbst aber war darum doch nicht gänzlich aufgehoben, sondern nur behindert und eingeschränkt.

In der Ucker- und Neumark waren die Bauern im Mittelalter ebenfalls freie Leute. Es ist dies nicht nur von den deutschen, sondern auch von den Bauern wendischer Abkunft $\mathrm{zu}$ behaupten. Von einer Leibeigenschaft der letzteren ist uns nichts überliefert. Vielmehr darf man das Gegentheil abnehmen aus dem Rechtsspruch, welchen der Landvogt Lippold von Bredow in Gemeinschaft mit mehreren markgräflichen Lehnsleuten und den Rathmannen von Prenzlau im Jabre 1383 kundgab. Es war damals in der Uckermark die Frage aufgeworfen worden, ob ein Bauer nach Erfüllung seiner Verbindlichkeit gegen den Grundherrn von dem Gute, das er von diesem empfangen und bis dahin bewirthschaftet hatte, frei hinwegziehen dürfe. Diese Frage wird zu Gunsten der Bauern ganz allgemein entschieden ${ }^{2}$, ohne dass irgendwie ein Unterschied gemacht würde zwischen solchen deutschen und wendischen Stammes. Auch mit dem Beginn der neueren Zeit scheint in den persönlichen Verhältnissen der Bauern in der Ucker- und Neumark zunächst noch keine Veränderung eingetreten zu sein. Die Landtagsiecesse des sechzehnten Jahrhunderts wissen noch nichts von einer Leibeigenschaft in diesen Landschaften. Die erste Andeutung von der Existenz

1) Korn a. a. O. S. 30 ff. - ${ }^{2}$ ) S. Wohlbrück, Geschichte des Bisthums Lebus I, S. 324-325. Die Worte des Rechtsspruches, auf die es hier ankommt, lauten danach, wie folgt: „Als wenn eyn bure wil tyhn vonn synes hern gude vnd hauen, So schal hie die plogen to dren fharen vnd schal sie tosegen mit der wintersaeth vnd schal dat frien efft ichts wes dar vp lige: vnnd schal dat gut verkopen efft hie kan vnd einen redlichen berueman dar vp bringen, die syne plege geuen mach, kan hie des nicht verkopen, So schall hie dat synen hern vpseggen vnd vpgeuen to Sunte peters dage, oder dar vor, vnd denn schall hie syne pacht geuen, die hie verpflicht ist, vnd denn fry wech tihn war hie wil mit synem gude, vnd weret dat syn her dat gut nicht wil vpnehmen so schal hie dat vp einen thun stecken vor Richter vnd vor den Buren vnd schall denn fry wech tyhn." 
einer dort aufgekommenen bäuerlichen Unfreiheit findet sich bei Joachim Scheplitz. In seiner um 1607 verfassten Compilation ${ }^{1}$ ) des märkischen Provincialrechts constatirt er, dass die Bauern in der Mark freie Leute seien. Es gebe dort, sagt er, niemand, der unfrei 'geboren sei. Er fügt dem alsbald aber die einschränkende Bemerkung hinzu: „Quod tamen de rusticis in Marchia Uccarina tum etiam in Nova Marchia ita absolute meo judicio vix dici potest" ${ }^{2}$ ).

$\mathrm{Zu}$ einer förmlichen Anerkennung der Leibeigenschaft durch die Gesetzgebung kam es jedoch während der ersten Decennien des siebzehnten Jahrhunderts noch nicht. Diese erfolgte erst unter der Regierung des grossen Kurfürsten Friedrich Wilhelm.

Die für die Kreise der Neumark, das Land Sternberg, auch die beiden Herrschaften Beeskow und Storkow am 16. Juni 1646 erlassene „Pauer Gesinde, Hirten und Schäffer Ordnung" "3) sprach sich über die „Dienstbahrkeit vnd Leibeigenschafft" dahin aus, es sollte diese „an denen Orten, da sie im Schwange nicht aufgehoben" sein, "besonders bey hergebrachten Gebrauche und Verordnung der vorigen LandtagesReversen ${ }^{4}$ ) vnuerschrenckt gelassen werden". Veranlasst war diese Bestimmung durch eine, drei Jahre zuvor an den Kurfürsten gerichtete Vorstellung der ucker- und neumärkischen Stände vom 11. April $1643^{5}$ ). Sie beschwerten sich darin, dass, obgleich sie von Alters her die Leibeigenschaft über ihre Unterthanen und deren Kinder gehabt, ,Etliche dem entgegen, ehe sie sich der Subjektion bei ihren Junkern los gemacht, in die Aemter und Städte zögen". Es knüpfte sich

1) Consuetudines Electoratus et Marchiae Brandenburgicae (Lipsiae, 1616) P. IV, Tit. VII, p. 444, \$2, nr. 3. S. hierzu Stobbe, Geschichte der deutschen Rechtsquellen II, S. $357 \mathrm{ff}$. _ ${ }^{2}$ ) Korn ist diese Bemerkung des Scheplitz entgangen, ebenso wie die noch zu erwähnende Stelle der neumärkischen Bauernordnung von 1646. - ${ }^{3}$ ) Mylius, C. C. V, Abth. IlI, S. 78. - 4) Diese enthielten die allgemeine Zusicherung, der Kurfürst wolle die Stände nicht nur bei ihren Privilegien und Gerechtigkeiten, sondern auch bei ihrem alten Herkommen und wohlhergebrachten Gebräuchen schützen. Der Leibeigenschaft wird dabei nicht speciell gedacht. Vgl. den Extract des Recesses vom 18. April 1643 bei Mylius, G. C. VI, Abth. I, S. 386 a. E. - ${ }^{5}$ ) S. diese bei Korn a. a. 0. S. 43. 
hieran die Bitte, der Kurfürst wolle an die Aemter und Städte Befehl ergehen lassen, „dass sie keinen, er komme wo er wolle, zum Unterthan, Bürger oder Diener annehmen, oder wo es schon geschehen, seinen Junkern wieder abfolgen lassen". Es folgte zehn Jahre danach der Landtagsrecess vom 26. Juli 1653, den der Kurfürst den Ständen der ganzen Mark diesseits und jenseits der Oder und Elbe ertheilte ${ }^{1}$ ). Von der Leibeigenscbaft wird darin nicht bloss mit Rücksicht auf die Neumark, sondern auch auf die Uckermark gesagt: „es solle an den Orten, wo sie introducirt und gebräuchlich verbleiben". Würde jemand dawider sich auf den Erwerb der Freiheit durch Verjährung berufen, ,so soll dazu nicht allein diuturnitas temporis, sondern auch bona fides, titulus, vel scientia et patientia domini" erfordert werden. Stand hierdurch die rechtliche Existenz der Leibeigenschaft in der Ucker- und Neumark fest, so war ihr doch darum noch nicht vom Gesetzgeber die Bedeutung eines allgemein gültigen Rechtsinstituts beigelegt. Sie sollte blos an den Orten gelten und zu Recht bestehen, wo sie sich in Gebrauch und Herkommen gründete. Nur mit dieser beschränkenden Massgabe erhielt sie später die erneute gesetzliche Bestätigung durch die „Revidirte Bauer-Ordnung" für die Mittelmark, Priegnitz und Uckermark vom 18. December 1682 Tit. I $\S 5^{2}$ ), durch die

1) Mylius C. C. VI, Abth. I, S. 426 ff. Vgl. dazu den den neumärkischen Städten ertheilten „Special-Revers, vom 29. August 1653, Nr. 16 (das. S. 482): „Die Klage über - Missbrauch der Leibeigenschaft wollen wir an unsere neumärkische Regierung remittiret haben, eine solche Verordnung nach Ausweissung der allgemein beschrieben Rechte und Landes-Reverse zu machen, wie dieselbe der Billigkeit gemäss ist, jedoch denselben, so der Leibeigenschafft Gerechtigkeit haben, an ihrer Observantz und erlangten Iure quaesito, allerdinge ohne Schaden, dafern aber die Leibeigenschafft nicht gebrauchlich, soll sie auch nicht eingefūhrt werden.“ S. ferner noch "Rescript an die Neumärkische Regierung zu Cüstrin in puncto iuris mancipii" vom 22. Januar 1655 (das. S. 496). Aus letzterem geht hervor, dass der Kurfürst auch für sich das Recht der Leibeigenschaft bezüglich der Bauern auf manchen seiner neumärkischen Domänenämter in Anspruch nahm. - $\left.{ }^{2}\right)$ Mylius C. G. V, Abth. III, S. 144. 145. Der Mittelmark waren schon damals ebenso wie später auch die ehemals lausitzischen Herrschaften Beeskow und Storkow zugetheilt. Sie hatten früher ein Zubehōr der Neumark ausgemacht. (Vgl. die Ueberschrift der vorhin citirten neumärkischen 
Revidirte Bauernordnung für die Neumark vom 14. September 1685 Tit. I $\S 5$, nebst dem Anhang dazu vom 29. Juni 1687 nr. $1^{1}$ ), endlich durch die, schon der Zeit des Königs Friedrich Wilhelm I. angehörende Revision der Gesinde- und BauernOrdnung der Mittelmark, Prignitz und Uckermark vom 24. August 1722 Tit. I $\S 5^{2}$ ).

Welcher Art war nun aber diese Leibeigenschaft? Es liegt uns hierüber eine Erklärung vor, welche die Ritterschaft der Uckermark an den grossen Kurfürsten richtete. Dieses Schriftstück, welches den Zweck hatte, die Besonderheiten der dortigen ländlichen Verfassung gegenüber den Rechten der Mittelmark darzulegen, wurde demnächst im Auszuge den Bauernordnungen für die Mittelmark, Prignitz und Uckermark u. s. w. von 1682 resp. 1722 Tit. I § 5 einverleibt.

Danach sind die unterthänigen Bauern der Uckermark mit sammt ihren Kindern vermöge der Leibeigenschaft an die Güter, denen sie zugehören, gebunden. Weil sie der Freizügigkeit gänzlich ermangeln, dürfen sie ihre Höfe weder verlassen, noch verkaufen, noch auch den Herren einen Gewährsmann an ihre Stelle verschaffen, um daraufhin die Mög-

Bauernordnung vom 16. Juni 1646). Trotzdem hat dort die Leibeigenschaft nirgends Geltung erlangt. Es ergiebt sich dies aus der Thatsache, dass die 1682 und 1722 für die Mittelmark, Prignitz und Uckermark, sowie für Beeskow und Storkow erlassene Revidirte Bauernordnung von der Leibeigenschaft nur allein mit Bezug auf die Uckermark und das Land Stolpe luandeln. Das Land Stolpe, mit der Stadt gleichen Namens, begreift die Gegend links der Oder zwischen Schwedt, Angermünde und Oderberg. Es bildete früher in administrativer und ständischer Hinsicht ein Zubehör der Uckermark und entsprach so den der Neumark zugelegten Gebieten von Sternberg, Grossen, Züllichau und Kottbus.

1) Mylius G. C. V, Alth. III, S. 172 und S. 215. Ob und wie weit die Leibeigenschaft ausser in der eigentlichen Neumark auch in ihren Nebengebieten (s. die vor. Note) locale Verbreitung gefunden hat, wird sich mit Sicherheit kaum mehr feststellen lassen. Nur von dem früher Jausitzischen Kreise Kotthus wissen wir, dass dort die Bauern der Leibeigenschaft im Sinne und in der Bedeutung, den das neuere deutsche Recht damit verband, unterworfen gewesen sind. Vgl. Verordnung vom 18. Januar 1819, betr. die Aufhebung der Erbuntertbänigkeit im Kottbuser Kreise (G. S. 1819, S. 21). - ${ }^{2}$ ) Mylius C. C. V, Abth. III, S. 269-270. 
lichkeit des Abzuges zu erlangen. Sie sind ferner ihren Herren zu ungemessenen Frohndiensten verbunden. Auch müssen sie es sich gefallen lassen, von einem auf den andern Hof oder sogar von einem in das andere Dorf versetzt zu werden. Das über das Wesen der Leibeigenschaft Gesagte wird zum Schluss in die Worte zusammengefasst, es verhalte sich damit in der Uckermark ebenso, wie es in Hinterpommern sowohl auf den Fürstlichen Aemtern als adeligen Gütern ,bewandt und Herkommens" wäre. Die pommersche Leibeigenschaft haben wir als eine blosse Gutsbehörigkeit kennen gelernt. Aus der Gleichartigkeit mit jener ergibt sich für die Leibeigenschaft der unterthänigen Bauern in der Uckermark dieselbe Natur und Bedeutung. Auch hier waren die Leibeigenen wohl glebae adscripti, nicht aber war etwa ihr Zustand identisch mit dem einer völligen Rechtlosigkeit.

Ueber das Wesen der Leibeigenschaft an den Orten der Neumark, wo diese hergebracht war, fehlt es in den Bauerordnungen an näheren Angaben.

Weder die ältere Bauerordnung von 1646 noch die neuere von 1685 enthält eine Definition derselben. Trotzdem wird man nicht daran zweifeln dürfen, dass die Leibeigenschaft dort, soweit sie überhaupt stattfand, von derselben Art und Beschaffenheit war, wie in der Uckermark. Es spricht hierfür der Umstand, dass in den der Neumark und ihren Nebengebieten benachbarten Ländern von Pommern und Schlesien die Leibeigenschaft keine Art der persönlichen Sklaverei war, sondern einer blossen Gutsbehörigkeit gleichkam. Freilich grenzt auch Westpreussen und Polen an die Neumark. Nichts aber deutet darauf hin, dass das polnische Recht der neueren Zeit mit seiner strengern Auffassung der Leibeigenschaft in der Neumark Eingang gefunden hätte.

Ist die Leibeigenschaft, wie man vermuthen darf, von aussen her nach der Neumark gekommen, so hat darauf doch jedenfalls nur die Rechtsentwickelung in den anstossenden deutschen Gebieten einen Einfluss gehabt. Für diese Annahme fehlt es denn auch nicht an einem positiven Anhalt. Er bietet sich dar in dem Sprachgebrauch der neumärkischen Bauernordnung von 1685. Da heisst es nämlich Tit. I $\S 9$, im un- 
mittelbaren Anschluss an die Bestätigung der Leibeigenschaft für diejenigen Orte, wo solche herkömmlich, es sollen die aus einem unehelichen Beischlafe gezeugten Kinder an den Orten unterthänig sein, wo sie geboren worden. Die Worte unterthänig und leibeigen werden demnach im selben Verstande genommen. Diese neumärkische Bauernordnung stimmt hierin überein mit der für die Mittelmark u. s. w. erlassenen von 1682 resp. 1722, denn letztere nennt die der Leibeigenschaft unterworfenen Bauern der Uckermark und des Landes Stolpe ebenfalls Unterthanen. Von der uckermärkischen Leibeigenschaft aber wissen wir, dass sie gleich der pommerschen einer blossen Gutsbehörigkeit gleichkam, ohne die Rechtsfähigkeit der ihr unterworfenen Leute aufzuheben. Werden nun in der Uckermark ebenso, wie in der nur durch die Oder getrennten Neumark, die Leibeigenen ausser mit diesem Namen mit dem der unterthänigen Leute bezeichnet, so kann diese Thatsache wohl als Argument für die Meinung gelten, dass in beiden Landschaften derselbe Ausdruck demselben Begriff, nämlich dem der Gutsbehörigkeit entsprach. Eine weitere Unterstützung erhält diese Annahme durch den Umstand, dass auch in den übrigen Ländern des östlichen Deutschlands ${ }^{1}$ ) die gleichzeitige Gesetzgebung mit den Worten Unterthan und Unterthänigkeit nichts anderes denn die Leibeigenschaft im Sinne des neueren deutschen Rechts bezeichnete, als gleichbedeutend mit Gutsbehörigkeit (glebae adscriptio).

Eine Ausnahme machte da allein Ostpreussen ${ }^{2}$ ). Die dortige Gesetzgebung aber konnte für das Recht der Neumark nicht in Betracht kommen. Hatte doch zu der Zeit, wo die Leibeigenschaft hier nachweislich zuerst aufkam, jede Verbindung zwischen beiden Ländern längst aufgehört.

Die Gleichartigkeit der uckermärkischen Leibeigenschaft mit der in Pommern macht es erklärlich, dass die Gesetzgebung König Friedrichs des Grossen ihr gegenüber ein

i) Bezüglich von Pommern ist da zu vgl. die Revidirte Gesindeordnung vom 7. Januar 1670 Tit. II, \$§ 1. 4; Tit. IV, \$§ 9. 10 (Dähnert, Sammlung Pomm. Landesurkunden III. Bd., II. Thl., S. 870.871 ff.). Von der Gesetzgebung Schlesiens und der Oberlausitz wird später die Rede sein. - ${ }^{2}$ ) Siehe meine Abhandlung in dieser Zeitschrift VIII, G. A., S. 55, Note 1 . 
ähnliches Verfahren eingeschlagen hat, wie das bei der pommerschen Bauernordnung von 1764 beobachtete. Vertauschte man dort den Namen Leibeigenschaft mit dem der Eigenbehörigkeit, ohne an Wesen und Inhalt derselben eine sachliche Aenderung vorzunehmen, so wurde hier die Bezeichnung Leibeigenschaft durch den Ausdruck Unterthänigkeit ersetzt. Es geschah dies gelegentlich der Revision der Gesinde- und Bauernordnung für die Mittelmark, Altmark, Prignitz, Uckermark vom Jahre 1769. Die förmliche Erklärung, dass die unterthänigen Bauern keine Sklaven seien, wie sie das neue pommersche Provincialgesetz enthielt, wurde dabei nicht für nöthig befunden. Der König und seine Berather hielten es für ausreichend, dass in dem neuen Gesetz wegen der Unterthänigkeit in der Uckermark auf die Bestimmungen der älteren Bauernordnung König Friedrich Wilhelms I. von 1722 verwiesen wurde $\left.{ }^{1}\right)$. Sie wollten damit offenbar andeuten, dass der in der früheren Gesetzgebung gebrauchte Ausdruck Leibeigenschaft eben nichts anderes bezeichne als Unterthänigkeit in dem Sinne der Gutsbehörigkeit. In der Neumark ist es nicht einmal zu dieser Namensänderung gekommen. Dort hat mit der fortdauernden Geltung der Bauernordnung von 1685 bis zum Erlass des Edictes vom 9. October bezw. der C.-O. vom 28. October 1807 die Unterthänigkeit oder Gutsbehörigkeit die officielle Bezeichnung Leibeigenschaft behalten ${ }^{2}$ ).

II.

War die Abschaffung der Leibeigenschaft in Pommern und der Uckermark eine bloss nominelle, so handelt es sich

1) S. die Revidirte Gesindeordnung für das platte Land der MittelAltmark, Prignitz, Uckermark vom 11. Februar 1769 (N. C. C. IV, S. 5336), Tit. I, § 1: ,lassen Wir es wegen der Dienste, worzu die Kinder der Bauern und Cossäten ihrer Gerichts-Obrigkeit verbunden, in gleichen wegen derselben und ilırer Kinder Unterthänigkeit bey demjenigen bewenden, was deshalb in der publicirten Gesinde-, Bauer-, Hirten- und Schäfer-Ordnung vom 24. August 1722 festgesetzt ist." 2) Nur hei dieser Erwägung wird es verständlich, dass die Redactoren der C. O. vom 28. October 1807 sich veranlasst sehen konnten, neben der Eigenbehörigkeit, Erbunterthänigkeit und Gutspflicht auch die Leibeigenschaft als ein auf den Domãnen noch fortbestehendes Verhältniss aufzuführen. 
dagegen bei den Reformen Friedrichs des Grossen bezüglich der unfreien Landbewohner in den Gebietserwerbungen des Jahres 1772 um gesetzgeberische Massregeln von schwerwiegender praktischer Bedeutung.

Zum Verständniss derselben ist es vor allem nöthig, dass wir uns mit dem Gegenstande der Reformen bekannt machen.

Welches war, fragen wir, der Zustand der leibeigenen Leute im Netzdistrict, in Westpreussen und im Ermlande vor der Vereinigung dieser Gebiete mit dem preussischen Staate?

Beginnen wir 1) mit dem Netzdistrict.

In diesem ehemals zu Grosspolen gehörigen Bezirke war bis $\mathbf{1 7 7 2}$ das polnische Recht das herrschende Landesrecht.

Wenn man früher wohl behauptet hat, die slavische Leibeigenschaft sei von Alters her einer völligen Knechtschaft und Sklaverei gleichbedeutend gewesen ${ }^{\mathbf{1}}$,, so ist diese Meinung, was Polen angeht, nicht gerechtfertigt.

Die mittelalterlichen Quellen des polnischen Rechts unterschieden Kmethones (Kmethen, Kmiecie) und servi, Leibeigene (slugi). Von den ersteren hatten manche das Recht der deutschen Colonisten erlangt. Gleich jenen waren sie freie Leute. Als solche konnten sie von ihren Bauerhöfen hinwegziehen. Nur waren sie gehalten, dieselben zu verkaufen, oder in sonstiger Weise für deren Uebernahme durch andere, gleich wohlhabende Wirthe Fürsorge zu treffen. Ohnedem waren sie contractlich verbunden, so lange zu bleiben, bis sie die zur Cultur erhaltenen Flächen vollständig gerodet und mit Winter- und Sommerkorn besäet hatten ${ }^{2}$ ).

Nicht dasselbe lässt sich von den nach polnischem Recht lebenden Kmethen sagen. Im allgemeinen ermangelten diese der Freizügigkeit. Nicht zwar immer an die Güter gebunden, welche ihnen zur Cultur und gegen Zins, später auch gegen Leistung von Frohndiensten eingegeben waren ${ }^{3}$ ), galten sie doch insoweit als grundbehörig, dass sie aus den Dörfern oder

1) S. die oben S.32. 33 citirte Vorstellung der Stände Vorpommerns. 2) Stat. Casimir. IIJ. Visliciae a. 1347 promulgat. c. 138 (Bandtkie, Ius Polon. p. 114-115). - s) Vgl. die in der folgenden Note citirten Statuten und bezüglich der Frohnden insbesondere Stat. Masoviae (Bandtkie 1. c. p. 434), Stat. Sigismundi I de laborib. Kmethon. (Leges Statut. ct. Poloniae ed. Konarski ('Tom. I) Varsaviae, 1732, p. 394). 
überhaupt aus den Dominien der Grundherren nicht frei hinwegziehen durften ${ }^{1}$ ).

1) Stat. Casimir. III, a. 1347 , c. $73.138,36$ (Bandtkie p. 74.75. 113-115. 136). Stat. Ioann. Albert. 1496, c. 19 (das. p. 343). Das im Text von der Grundbehörigkeit der nach polnischem Recht lebenden Kmethen Gesagte tritt der Ansicht entgegen, welche Macieowski, Slavische Rechtsgeschichte (ins Deutsche übersetzt von Buss u. Navrowki) S. 176 vertritt, dem Brueggeney dictus Hasenkamp in seiner Diss. inaugural. De rusticorum regni Pol. s. XIV-XVI conditione p. 12 beipflichtet. Diese genannten Schriftsteller nehmen den Mangel der Freizügigkeit bei den Kmethen nur für so lange an, als sie ihre contractlichen Verpflichtungen gegen ihre Grundherren noch nicht erfüllt hatten. Sonst habe ihnen der Abzug freigestanden. Diese Meinung ist jedoch nicht in Einklang zu bringen mit dem Inhalt der oben citirten Statuten des Königs Kasimir III. und Johann Albert. Denn hiernach soll, von gewissen Fällen abgesehen, immer nur einzelnen Kmethen eines Dorfes das Verlassen desselben wider den Willen des Herrn gestattet sein. Es liegt aber überdies ein Quellenzeugniss vor, worin deutlich unterschieden wird zwischen dem Verlassen des einzelnen betreffenden Gutes, das der Kmethe zur Cultur vom Herrn empfangen hat, und dem $\mathbf{A b}$ zuge aus dessen Grundherrschaft überhaupt. War der Kmethe zum Verlassen des von ihm innegehabten Gutes schon befugt nach Erfüllung der ihm vertragsmässig obliegenden Verbindlichkeiten, so hing dagegen die Entscheidung der Frage, ob er sich auch aus dem herrschaftlichen Gutsbezirke entfernen durfte, von den Vorschriften des Landrechts bezw. von dem Inhalt des in der Grundherrschaft geltenden Statutarrechts ab. Vgl. Stat. Vlad. Iag. 1420 (Bandtkie p. 215), c. 23: ,- si quis kmetho in silva, ubi villa locari debeat, libertatem accipiat, non poterit de suo agro, nisi illum extirpaverit se movere, quo extirpato facere poterit, quod ius terrestre, aut jllius haereditatis exquirat et deposcit circa suam motionem." - Immer freilich bildete die Grundbehőrigkeit der polnischen Kmethen nur die Regel. In einzeinen Gegenden, in Masovien und in der Nähe von Krakau, waren sie günstiger gestellt. Ihre Freizügigkeit war dort in der That nur so lange beschrãnkt, als sie ihre contractlichen Verpflichtungen gegen die Grundherren noch nicht erfüllt hatten. Vgl. Stat. Ioann. Albert. a. 1493, c. 12 (Bandtkie p. 327), Stat. domin. duc. Masov. (das. p. 435. 437). S. dazu auch noch: Constitut. terrae Lanciciensis a. 1418. 1419, 34-35. 37. 65. 67 (das. p. 197. 200). Was Masovien angeht, so hörte dort diese, wenn auch nur beschränkle Freizügigkeit der Kmethen im XV. Jahrhundert auf. Sie gelten seitdem für unbedingt an die Scholle gebunden. Es steht ihnen, um den Abzug auch olme die Genehmigung der Herren zu erlangen, nicht mehr frej, sich darauf zu berufen, dass sie ihren Verbindlichkeiten nachgekommen, und die Herren desshalb nicht mehr berech: tigt seien, sie zum Bleiben im Bereiche ihrer Dominien zu nöthigen. 
Verglichen mit dem Zustande der eigenen Leute in Deutschland in den Zeiten des Mittelalters war die Lage der polnischen Kmethen insoweit eine günstigere, als das Verhältniss, in dem sie als glebae adscripti zur Grundherrschaft standen, kein schlechthin unaufiösliches war. Eine Constitution des bauerfreundlichen Königs Kasimir III. (des Grossen) bestimmte, in jeder Dorfschaft solle alljährlich zwei Kmethen der Abzug freistehen, ohne dass sie dazu die Einwilligung des Grundherren einzuholen nöthig hätten ${ }^{1}$ ). Später entstandenes Gewohnheitsrecht und darauf gegründetes Gesetz räumten diese Abzugsfreiheit wenigstens noch einem Kmethen ein ${ }^{2}$ ). Unter Umständen waren sogar die sämmtlichen Kmethen einer Dorfschaft berechtigt, sich ihrer Grundherrschaft wider deren Willen zu entziehen. Die Statuten des genannten Königs Kasimir III. räumten ihnen die Befugniss hierzu in bestimmten Fällen eines verbrecherischen oder schuldhaften, bezw. sündhaften Verhaltens der Grundherren ein, ohne Rücksicht darauf, ob davon einzelne Kmethen unmittelbar betroffen waren oder nicht ${ }^{3}$ ). Zugleich wurde in derselben Gesetzgebung das herrschaftliche Abforderungsrecht gegenüber solchen Kmethen, die ihren Herren entwichen waren, ohne dass auf Seiten der

S. Stat. Mazov. per dom. duces Vladislaum et Boleslaum a. 1452 (Bandtkie p. 439).

1) Stat. Casimir. III, a. 1347, c. 73 (Bandtkie p. 74-75): „- statuimus: quod non plures kmethones aut incolae de una villa insimul ad aliam villam possint recedere, nisi unus aut duo praeter domini illius villae, in qua degunt, voluntatem." - 2) Stat. Ioann. Albert. a. 1496 , c. 23 (Bandtkie p. 349): „Item innitendo constitutioni Magni Casimiri regis - statuimus: ut, quemadmodum ex consuetudine fieri consuevit, sic etiam perpetuo observetur, quod non plures, quam unus kmetho, annis singulis, se de una villa in aliam transferre poterit iure atque licite." - ${ }^{\text {a) }}$ Stat. Casimir. III, a. 1347, c. 138 (Bandtkie p. 115): „Culpae - propter quas a domino suo fugere licitum sit kmethoni, sunt istae: prima quando dominus propter suum excommunicatur delictum, et ob hoc kmethones ecclesiastica privantur sepultura; item secunda, quando dominus villae in quocunque loco suam villanam oppresserit violenter, et cum primum de hoc constiterit, nedum parentes oppressae, verum etiam omnes villani, ubi hoc scelus commissum fuerit, quacunque hora recedendi liberam habeant facultatem - Idem liceat ipsis kmethonibus facere, cum ob culpam sui domini pignora de eis fuerint recepta." cf. dieselben Stat. c. 73. 
letzteren eine Schuld vorlag, auf die Zeit eines Jahres seit erlangter Kenntniss von ihrem Aufenthalte eingeschränkt. War diese Frist versäumt, so konnte der entflohene Bauer zur Rückkehr nicht mehr gezwungen werden. Er verfiel bloss in eine Geldbusse und hatte sich seiner vertragsmässigen Verbindlichkeiten gegen den Herrn durch Leistung eines Jahreszinses $\mathrm{zu}$ entledigen ${ }^{1}$ ).

Sehen wir $a b$ von ihrem Verhältniss als grundbehöriger Leute, das sich nach den eben besprochenen Vorschriften als kein unbedingt unlösliches darstellt, so waren die Kmethen in ihrer Rechtsfähigkeit nicht gemindert. Wie sie Vermögen erwerben und besitzen konnten, waren sie auch berechtigt, ihren Nachlass auf ihre Kinder und sonstige Anverwandte zu vererben ${ }^{2}$ ).

Wirthschaftlich und rechtlich schlechter gestellt als die Kmethen waren die Leibeigenen auf den Gütern der Grundherren. Hatten die ersteren als Bauern Güter inne, die sie

1) Dieselben Stat. c. 138 (Bandtkie p. 113): „- statuimus: quod cum a nobis, sive a quocunque alio domino, nobis subdito, kmetho effugerit, absque culpa sui domini, idem kmetho fugiens nullum ius acquirat tamdiu, donec domino suo de mansione ipsius non constabit, secus si domino suo de mansione ipsius constiterit, et intra annum ipsum iure non repetierit; ex tunc post annum, si ipsum repetere voluerit, minime sibi hoc facere licebit; qui profugus si, propter austeritatem seu rancorem domini sui, redire timens etiam iure convictus noluerit, extunc decernimus: quod idem fugiens domino suo tres marcas pro poena, et censum annalem integre quem alias solvebat, solvere tenebitur, et per hoc a domino suo fugitivus liberabitur antedictus." Ueber die richtige Auslegung dieser Stelle vgl. das Marginale dazu bei Bandtkie. Früher hat man sie irrthümlich dahin verstanden, als habe sich jeder entwichene Kmethe auch vor Ablauf der einjährigen Abforderungsfrist durch Zahlung der Strafe und eines Jahreszinses loskaufen können, wenn er von seinem Herrn mit ungebührlicher Härte behandelt war und darum die Rückkehr scheuen mochte. S. Dresner, Inst. iur. Pol. p. 56, Not. f. und p. 62-63, Note g. Jener Schriftsteller wollte daher diesen Fall den im selben Statut angeführten Fällen zurechnen, wo die Kmethen wegen einer Schuld ihrer Herren zum Verlassen derselben befugt sein sollten. - 2) Das von manchen Grundherren beliebte Verfahren, den beweglichen Nachlass ihrer Kmethen einzuzielıen, wenn diese kinderlos verstarben, ward von König Kasimir III. für einen Missbrauch erklärt und verhoten. Stat. Casimir. III., c. 55 (Bandtkie p. 65-66). 
gegen Zins, bezw. gegen die Verpflichtung zu Frohndiensten bewirthschafteten, so waren die letzteren an sich blosse Knechte, die auf den Herrschaftshöfen oder bei der Person der Grundherren Dienste der einen oder der anderen Art leisten mussten. $\mathrm{Ob}$ und wo der Herr dem einzelnen Leibeigenen ein Grundstïck zur Bebauung anweisen mochte, stand in seinem Belieben $\left.{ }^{1}\right)$. Ein anderer Unterschied zwischen beiden Arten von unfreien Leuten war folgender: Die Kmethen durften, wie wir gesehen haben, unter gewissen Umständen von den Höfen und aus den Dörfern, wohin sie angesiedelt waren, wider den Willen der Grundherren wegziehen. Dahingegen war den Leibeigenen die Möglichkeit, sich der Gewalt, in der sie standen, zu entledigen, völlig verschlossen. Sie konnten nicht anders zur Freiheit gelangen, als wenn die Herren aus freien Stücken sie ihrer Gewalt entliessen. Fin Statut des Königs Vladislaus Jagello vom Jahre 1420 erkannte dies ausdrücklich an, unter Berufung auf die Vorschriften des Kaiserrechts (lex imperialis), d. h. des römischen Rechts über die Sklaverei ${ }^{2}$ ). Trotzdem war der Zustand, in welchem sich die polnischen Leibeigenen während des Mittelalters befanden, kein völlig rechtloser ${ }^{3}$ ). Die sehr dürftigen Mittheilungen, welche uns die polnischen Rechtsquellen aus jener Zeit geben, lassen doch so viel erkennen, dass die Herren sie nicht willkürlich tödten,

1) S. das in der folgenden Note angeführte Statut. - ${ }^{2}$ ) Stat. Vladisl. Iagell. a. 1420, c. 31 (Bandtkie p. 219): „In lege imperiali continetur: quod servi illiberi, aut ancillae, non possint nec valeant de manibus dominorum suorum liberari, nisi per eosdem fuerint manumissi, et libertate donati, sed quia multoties tales illiberi, manus suorum dominorum subterfugientes, et evadere volentes apud alienos terrigenas et vicinos latitant - ex quorum fuga domini non modica damna percipiunt - cum servos illiberos dominus, ubi vult, locare potest acquirendo haereditatem novam, per ipsos errigendam; unde si apud aliquem tales de caetero latitabunt, aut servabuntur, idem debet eosdem retinere, et in curia proximiori domini regis protestari, quod tales habeat retentos et servat, quod si ille facere omiserit, et dominus servorum per testes approbaverit contra ipsum illiberum, domino cuius fuerit, solvere tenebitur cum poena pietnadziesta." _ Macieowski, Slawische Rechtsgeschichte I, $\S 71$, S. $138-140$ und die bereits angeführte Dissertation von Brueggeney (Hasenkamp) p. $20 \mathrm{vgl}$. mit dem Inhalte der in der folgenden Note angeführten Stellen aus den masovischen Statuten. 
verwunden oder gefangen halten durften ${ }^{1}$ ). Auch müssen die Leibeigenen vermögensfähig gewesen sein. Es ist dies daraus abzunehmen, dass sie in Hinsicht der Strafgelder, die jemand für ihre widerrechtliche Gefangenhaltung oder Verwundung zu zahlen hatte, mit den im übrigen rechtlich besser gestellten Kmethen auf ein und demselben Fusse behandelt wurden. Wie diese, hatten auch die servi selbst und nicht etwa bloss ihre Herren einen Anspruch auf Zahlung der wider sie verwirkten Strafen, neben und ausser dem ihnen etwa sonst noch gebührenden Schmerzensgelde ${ }^{2}$ ).

Ist hiernach die Meinung nicht gegründet, die Leibeigenen in Polen seien während des Mittelalters Sklaven gewesen, so musste es dagegen für die Folgezeit für sie verhängnissvoll werden, dass man seit dem fünfzehnten Jahrhundert anfing, die Grundsätze des römischen Sklavenrechts auf sie anzuwenden ${ }^{3}$ ).

Indessen nicht diese Thatsache allein war es, die für das Schicksal der Leibeigenen nicht nur, sondern auch für das der Kmethen auf den Gütern des polnischen Adels entscheidend werden sollte. Es trafen noch andere Umstände zusammen, um das endliche Resultat herbeizuführen, dass etwa vom Ende des sechzehnten Jahrhunderts ab die Kmethen so gut, wie die Leibeigenen der schrankenlosen Gewalt ihrer adeligen Herren unterworfen wurden.

Das Königthum, dem es im Mittelalter nicht an thatkräftigen Vertretern gefehlt hatte, die, wie Kasimir 11I. (der

1) Stat. Mazoviae (Bandtkie p. 412): „Quando nobiles citantur ad terminos communes pro percussione, aut interfectione kmethonum, servorum, oppidanorum et subditorum suorum - pro captivitate kmethonum et aliorum subditorum - pro istis omnibus, et aliis causis, his similibus, ordinem terrestrem tangentibus, tenentur respondere in eisdem terminis communibus ct. $-{ }^{2}$ ) Stat. Mazoviae (Bandtkie p. 412): „Ex consuetudine terrae non debet quisquam kmethones et servos captivare, et carceribus mancipare, tam in suis, quam alienis bonis, praecipue in laboribus domini sui, praeter causas recentis et domesticae violentiae, ant criminales. Et si quis contrarium fecerit, lenebitur domino captivi kmethonis duas sexagenas grossorum, a quolibet captivo, et pro illicita mancipatione captivo sexagenam, et vulnera specialiter, cum poena percussionis, solvere tenebitur." - $\left.{ }^{3}\right) \mathbf{S}$. das oben S. 52, Note 3 angeführte Statut des Königs Vladislaus Jagello von 1420 . 
Grosse), ihren Willensäusserungen und Verordnungen Achtung $\mathrm{zu}$ verschaffen wussten, verlor seit dem Ende des fünfzehnten und im Laufe des sechzehnten Jahrhunderts mehr und mehr an Ansehen und Macht. Nach dem Erlöschen des Jagellonischen Geschlechts (1572) erhielt das Recht der Reichsstände zur Wahl des Königs, welches bis dahin mehr ein blosses theoretisches Axiom gewesen war, praktische Bedeutung. Mit dem schwindenden Einfluss der Könige stieg andererseits die Macht und die Bedeutung des Adels. Verdankte dieser Stand schon der nachsichtigen Schwäche Sigismunds I, und Sigismund Augusts die umfassendsten Freiheiten und Privilegien, so steigerte sich seine Gewalt nach dem Jahre $1572 \mathrm{zu}$ einer fast schrankenlosen. Er wird fortan der im Reichstage und bei der Königswahl ausschlaggebende Factor. Schon allein diese übermächtige und massgebende Stellung des Adels im öffentlichen Leben Polens schloss für die von ihm abhängenden Kmethen und Leibeigenen eine ernste Gefahr in sich. Konnte der Adel doch nunmehr seine Macht und seinen Einfluss, den er im Reichstage auf die Gesetzgebung erlangte, dazu benutzen, um allen Massregeln zu begegnen, welche die Könige etwa zum Schutze der Bauern ins Werk setzen mochten ${ }^{1}$ ).

Selbst die erlangte massgebende politische Stellung würde jedoch für sich allein den Adel vielleicht noch nicht in den Stand gesetzt haben, seine Kmetben und Leibeigenen in völlige Sklaverei herabzudrücken, hätten die letzteren statt den ohnmächtig gewordenen König, unabhängige Richter um Hülfe gegen Bedrückung und Vergewaltigung von Seiten ihrer Grundherren anrufen können. Auch diese Möglichkeit aber sollte ihnen verschlossen werden. Hatten die Kmethen ursprünglich den gemeinsamen Gerichtsstand mit den Adeligen vor den Landgerichten (iudicia terrestria), so trat hierin mit dem

1) Nicht allein, dass alle Versuche, im Wege der Gesetzgebung die Lage der Bauern zu verbessern, vereitelt wurden, so mussten die Könige sich jetzt auch dem Adel gegenüber verpflichten, künftig nicht mehr, wie sie dies früher gethan hatten, den entwichenen Bauern und Leibeigenen Geleitsbriefe (salvos conductus) zu ertheilen, um sie vor dem Zorn und der Kache ihrer Herren zu schützen. Vgl. Stat. Alexandri 1505 (Leges [ed. Konarski] I, p. 302), Stat. Sigismundi 1543 (das. p. 576) und dazu Brüggeney (Hasenkainp) a. a. 0. p. 33. 
fünfzehnten Jahrhundert eine Aenderung ein. Sie wurden seitdem der Patrimonialgerichtsbarkeit ihrer Grundherren unterworfen ${ }^{1}$ ).

Schon nach dem mittelalterlichen Rechte Polens unterlagen sie ferner gewissen Beschränkungen, wenn sie als Kläger, bezw. als Ankläger vor Gericht auftreten wollten. Sie durften nicht selbst klagen, sondern hatten die Klageerhebung ihren Herren zu überlassen in allen Fällen, wo Streitigkeiten in Frage kamen, bei welchen die letzteren als Grundeigenthümer interessirt waren ${ }^{2}$ ). Dabei war es einerlei, ob die zu verklagende Partei dem Adel angehörte oder nicht.

Noch mehr eingeschränkt war ihre Klage- und Anklagebefugniss in Ansehung adeliger Personen. Es war den Kmethen nicht gestattet, Adelige um begangener Verbrechen willen vor Gericht zu laden oder sie in solchen Processsachen zu belangen, welche die Ehre berührten. Von dem guten oder bösen Willen der adeligen Herren hing es $a b$, ob diese die Rechte ihrer Bauern vor Gericht vertreten und statt derselben dort Anklage oder Klage gegen einen ihrer Standesgenossen erheben mochten oder nicht ${ }^{3}$ ). Immer freilich wurde dabei vorausgesetzt, dass der zu belangende Adelige ein anderer war, als der eigene Grundherr des beleidigten Kmethen. Denn dass der Bauer dem eigenen Herrn gegenüber nicht ohne jeden Rechtsschutz sein sollte, ergab sich aus den gesetzlichen Vor-

1) S. Macieovski, Slawische Rechtsgeschichte IV, S. 161. Brueggeney (Hasenkamp) a. a. 0. p. 18. 25. - ${ }^{2}$ ) Stat. Mazoviae (Bandtkie p. 403): „Quando nobilis vel quiscumque alius receperit subditis et kmethonibus alterius res aliquas, vel retia, aut aliqua alia instrumenta aquatica, in fluvio, vel in aliis locis, pro quibus inter partes praedictas controversia fuerat mota, vel non mota, non kmethones illi agere debent pro tali violentia et iniuria, sed domini eorum, quia actio haereditaria est, quae non competit kmethonibus. Et similiter intelligendum est de aliis bonis, videlicet sylvis, borris, gais, mellificiis, et his similibus.“ Wenn auch zunächst, wie es scheint, nur für Masovien bestimmt, erhielten die hier gegebenen Verordnungen durch Kraft des Gewohnheitsrechts in Polen überhaupt allgemeine Geltung. S. Herbert de Fulstein, Stat. regni Pol. p. 70. 240. S. ferner Process. iudicar. Sigism. I. a. 1523 (Leges ed Konarski I, p. 426 verb.: Ad instantiam laboriosi N. de N. Kmethonis ct.). - ${ }^{3}$ ) Stat. Mazoviae (Bandtkie p. 403): „pro causis criminalibus et honorem tangentibus kmethones et oppidani non possunt citare nobilitatem sed domini eorum." 
schriften, welche von der gerichtlichen Verfolgung der Herren wegen Tödtung oder. Verwundung ihrer Kmethen und Leibeigenen handelten ${ }^{1}$ ): Ueberdies besagte ein Statut des Königs Alexander ${ }^{2}$ ) vom Jahre 1505, es solle den unfreien Leuten der Weg der Beschwerde gegen ihre Herren bei Gericht offen stehen. Nichtsdestoweniger geschah es nicht allzulange nachher und zwar unter der Regierung der späteren Könige Sigismund I. und Sigismund II. August, dass es herrschender Grundsatz wurde, kein Kmethe oder Leibeigener solle mehr seinen adeligen Herrn in Processsachen irgendwelcher Art vor Gericht laden dürfen. In gesetzlicher Anordnung beruhte dies nicht. Es handelte sich dabei lediglich um ein Gewohnheitsrecht, von dem Macieowski ${ }^{3}$ ) sagt, er wisse nicht, wie dasselbe entstanden sei. Man wird den Grund desselben vermuthlich in einer falschen Auslegung und ungebührlichen Ausdehnung der vorhin besprochenen Vorschriften des älteren Rechts suchen dürfen ${ }^{4}$ ). Indem man gegenüber adeligen Personen schlechthin und in allen Fällen den Bauern und Leibeigenen die Fähigkeit absprach, ohne Beistand ihrer Herren vor Gericht als Kläger oder Ankläger aufzutreten, gelangte man zu der Annahme, sie ermangelten dieser Fähigkeit selbst den eigenen Herren gegenüber. Auch in Ansehung dieser, die ja ebenfalls zum Adel gehörten, sei ihnen der Rechtsweg verschlossen.

Zur besseren Rechtfertigung dieser Meinung aber musste das römische Recht dienen. Es waren namentlich die Stellen des corpus iuris civilis, worin die Gewalt der Herren über die Sklaven und das daraus fliessende ius vitae et necis auf das ius gentium zurückgeführt wird, aus dem man eine allgemeine für alle Zeiten und Länder, und so auch für Polen geltende Rechtswahrheit abstrahiren zu dürfen meinte ${ }^{5}$ ). In

1) Stat. Mazoviae (Bandtkie p. 412) oben S. 53, Note 1. - 2) Leges ct. (ed. Konarski) (I) p. 302. - ${ }^{3}$ ) Slawische Rechtsgesch. IV, S. 162. 4) Ausschlaggebend war es da, dass Jac. Pryluski (Jac. Prilusius) in seiner Zusammenstellung der polnischen Statuten Lib. I, c. 2, art. IV den oben S. 55, N. 2 aus den masovischen Statuten angeführten Bestimmungen eine allgemeinere Bedeutung gab. Er fasste sie in den Satz zusammen: „Kmetones assistentia dominorum suorum adiuti possint iniurias suas de nobilibus in iudicio terrestri persequi." 5) S. Thomas Dresner, Inst. iur. Pol: p. 56, Note 3, woselbst dieser 
der That vindicirten sich denn auch bald die polnischen Grundherren die Gewalt über Leben und Tod ihrer unfreien Leute; ohne dass ihnen das Recht hierauf, wie es scheint, von irgend einer Seite wäre streitig gemacht worden. Schon Cromer, der sein Werk über Polen, seine Geschichte und Geographie um 1550 verfasste, konnte sagen: „habent sane in eos Domini vitae necisque potestatem"1). Die Entwickelung der Unfreiheit der Kmethen und Leibeigenen des Adels, zwischen denen jetzt jeder Unterschied fortfiel ${ }^{2}$, zu einer völligen Knechtschaft und Sklaverei war hiermit zum Abschluss gebracht. Durften die polnischen Grundherren ihre unfreien Leute willkürlich tödten ${ }^{3}$ ), so wurde ihre Gewalt über diese zu einer völlig schrankenlosen. Thomas Dresner, ein polnischer Jurist, der zu Anfang des siebzehnten Jahrhunderts lebte, stellte sie denn auch geradezu der Gewalt gleich, welche bei den Römern die Herren über ihre Sklaven hatten ${ }^{4}$ ).

juristische Schriftsteller sich zum Beweise des Satzes, dass den polnischen Leibeigenen gegen ihre adeligen Herren keine actio iniuriarum zustehe, ausser auf die in der vorigen Note citirte Stelle aus den Stat. Pryluski und auf den usus, auf $1.1, \S 1$ D. de his qui sui vel alien. iur. $(1,6)$ beruft.

1) S. dessen Polonia und zwar den Abschnitt: De situ Pol. Lib. I, p. 499 (citirt nach der Ausgabe: Coloniae Agr. 1589). - ${ }^{2}$ ) Beide Arten von unfreien Leuten werden fortan nnter denselben Begriff zusammengefasst und mit dem gemeinsamen Namen der chlop (Bauern) oder Unterthanen (subditi) bezeichnet. S. Grorner a. a. O. p. 499, ferner Brueggeney (Hasenkamp) in seiner angeführten Diss. p. 22. 30 und Th. Dresner, Inst. p. 56. - ${ }^{3}$ ) Das polnische Recht ging hierin noch über das römische Recht, zum wenigsten über das der Kaiserzeit hinaus. Sind auch die von Hadrian und Antoninus Pius zum Schutze der Sklaven gegen das Wüthen ihrer Herren getroffenen Verordnungen wesentlich nur als polizeiliche Massregeln zu erachten, ähnlich etwa unsern Gesetzen gegen Thierquälerei, so wird doch schon seit Constantin die willkürliche Tödtung eines Sklaven durch den Herrn als homicidium bezeichnet. Auch sprechen die justinianischen Institutionen ( 2 De his qui sui vel alien. jur. I, 8) nicht mehr wie die des Gajus (I, 53) von einem blossen Haftbarwerden (teneri) der Herren, die ihre Sklaven tōdten. Sie sagen vielmehr geradezu, der Herr, der seine Sklaven ohne Grund tõdte, solle bestraft werden (puniri jubetur). S. auch noch 1 . un. C. de emendat. servor. $(9,14)$. - $)$ Inst. iur. regn. Pol. p. 56. 57: „Ut breviter dicatur, quae antiquis Romanis in servos fuit, haec nunc Nobilibus Polonis in Plebeios subditos absoluta est, quoad jus attinet, potestas." 
Nur eine Consequenz, die man aus dem ius vitae et necis zog, war, dass man die Leibeigenen jetzt schlechterdings für nicht fähig, noch berechtigt erklärte, anders denn im Beistande ihrer Herren vor Gericht, sei es in der Rolle des Klägers, sei es in der des Beklagten, aufzutreten, ohne dass es weiter darauf ankam, ob ihre Processgegner dem adeligen Stande angehörten oder nicht ${ }^{1}$ ). Die Gewährung dieses Beistandes war rein Sache des freien Beliebens der Herren. Es war darum für die unfreien Leute gleichbedeutend mit dem Verluste jeder Processfähigkeit, wenn man ihnen die Möglichkeit abschnitt, sich selbst vor Gericht zu vertreten. Und da in Strafsachen ${ }^{2}$ ) das Anklageverfahren vorherrschte, hörte mit dem Verluste der Processfähigkeit für sie zugleich die Parteifähigkeit im Strafprocess so gut, wie im Civilprocess auf. Dies aber musste sie nothwendiger Weise gänzlich rechtlos machen. Vermöge juristischer Fiction wurden sie so angesehen, als hätten sie eine capitis deminutio maxima erfahren ${ }^{3}$ ).

Weitere Folgerungen aus dieser Rechtlosigkeit ergeben sich von selbst. Nicht darf es uns daher überraschen, dass die Grundherren anerkanntermassen für befugt galten, ihre

1) Dresner, Inst. iur. Pol. p. כ̌6, wo er von den Leibeigenen sagt: „quorum capita domini sunt, sine quorum assistentia sive actores, sive rei sunt, contra quasvis personas locum standi in iure ac iudicio Terrestri non habent." - ${ }^{2}$ ) S. Holsche, Geographie und Statistik von West-, Süd- und Neuostpreussen II, S. 188. Die Einrichtung der bei den Gerichten angestellten sog. Instigatoren, denen die Aufgabe zufiel, begangene Verbrechen aufzudecken und zu verfolgen, fällt schon in die Zeit, nachdem die Rechtlosigkeit der Leiheigenen eine vollendete Thatsache geworden war. Die erste Nachricht davon findet sich bei Cromer a. a. 0. p. 517, zu dessen Zeit das ius vitae et necis der adeligen Grundherren bereits feststand (s. oben S. 57, Note 1). Die fragliche Institution vermochte so nichts mehr an dem Zustande der unfreien Bauern zu ändern. Uebrigens gab es keineswegs bei allen polnischen Gerichtshöfen Instigatoren. Namentlich fehlten diese bei den Landgerichten (iud. terrestria). S. Macieowski IV, §92, S. 114. - 3) Dresner, 1. c. p. 56 : ,subditi capita etiam non habere juris fictione dicuntur". Derselbe in Note $\mathrm{c}$ das., wo er auf die römischrechtlichen Vorschriften über die cap. deninutio (I. 3 D. de cap. minut. $(4,50)$, I. 59 D. de cond. et demonstr. (35, 1) verweist. S. dazu auch noch Brueggeney (Hasenkamp) J. c. und die dort angeführten Worte des Pryluski: „Rustici continua servitute premuntur et fictione iuris pro nullis habentur." 
unfreien Bauern und Unterthanen getrennt von den Gütern, auf welchen sie sich befanden, an andere $z u$ verkaufen, zu verschenken oder sonstwie zu veräussern ${ }^{1}$ ).

Gleichwie über deren Leben stand diesen auch über ihr Hab und Gut und alles, was sie etwa erwarben, das Recht der willkürlichen Verfügung zu. Jene aber ermangelten jeglicher Vermögensfähigkeit ${ }^{2}$ ). Hatte ferner schon die frühere Gutsbehörigkeit der Bauern sich auf deren Nachkommenschaft mit erstreckt ${ }^{3}$ ), so war es selbstverständlich, dass die Umwandlung jenes Verhältnisses in eine Sklaverei jetzt die Kinder derselben ebenfalls zu Sklaven machte und sie der unbedingten Botmässigkeit der Herren überantwortete, auf deren Grunde sie geboren waren ${ }^{4}$ ).

Die Unterwerfung der Kmethen und Leibeigenen des Adels unter dieselbe Sklaverei musste endlich auch die Geltung der älteren Statuten ausser Kraft setzen ${ }^{5}$ ), welche den ersteren unter gewissen Umständen den freien Abzug ohne und wider den Willen der Herren offen gelassen hatten.

1) Dresner 1. c. p. 56: „Yidem subditi a Dominis alienantur, comparantur, emuntur, venduntur.“ $\left.-{ }^{2}\right)$ Dresner l. c. p. 56 : „Erit igitur potestas Dominorum in subditis ea, quae vitam et fortunam eorum subjicit voluntati et arbitrio dominorum." - 3) Stat. Ioann. Albert. 1496 c. XIV (Bandtkie p. 343). Stat. Procerum Regni Pol. 1503 absente Alexandro Rege: De filiis Kmethonum (Leges ct. [ed. Konarski] [I] p. 293) Herbert de Fulstein, Stat. verb. Kmetho p. 237. 238. - ') Dresner 1. c., p. 55. 56: „Liberi quoque eorum in Dominorum recidunt potestatem, in quorum fundis nati sunt." $-{ }^{5}$ ) Diese sind niemals förmlich aufgehoben worden. Wie sich die Umwandlung der Gutsbehörigkeit der Kmethen in Leibeigenschaft und Sklaverei rein im Wege des Gewohnheitsrechts vollzog, so erfolgte auf demselben Wege die Abschaffung jener älteren Satzungen. S. Dresner l. c. p. 62. Zu den so ausser Anwendung tretenden Statuten wird man auch eine Verordnung zu reclinen haben, welche vom König Sigismund I. herrührte und vom Jalıre 1511 datirte (Herbert de Fulstein, Stat. verb. Kmetho p. 238, Leges ct. [ed. Kornarski] [I], p. 379). Die darin im Princip anerkannte Freiheit der Eheschliessung auf Seiten der Kmethen (welche nur insoweit beschränkt war, dass bei der Heirath der Tochter eines ansässigen mit einem nicht angesessenen Bauern, der letztere zu ihr auf des Vaters Gut ziehen sollte), war mit dern Wesen der Leibeigenschaft als Sklaverei nicht vereinbar. Es ist daher davon auch später keine Rede" mehr. Weder Dresner noch andere polnische Juristen des siebzelhnten und achtzehnten Jahrhunderts gedenken mehr des Inhalts jener Verordnung. 
Wie schon früher die Leibeigenen (servi) ${ }^{\mathfrak{1}}$ ), konuten nunmehr die unfreien Bauern und Unterthanen des Adels überhaupt regelmässig nur durch die allein vom Willen des Herrn abhängende Manumission zur Freiheit gelangen. Sogar die Verjährung, welche zu Zeiten der Römer den Sklaven den Weg zur Freiheit eröffnet hatte ${ }^{2}$ ), sollte seit dem Erlass eines Reichsgesetzes vom Jahre 1633 ihnen nicht mehr die Freiheit verschaffen ${ }^{3}$ ).

Nur in einem Falle ward auch später noch von der Nothwendigkeit der Manumission abgesehen. Wenn ein Leibeigener sich mit Erfolg wissenschaftlichen Studien widmete und daraufhin einen akademischen Grad erlangte oder Geistlicher wurde, sollte er der Gewalt seines Herrn ohne weiteres ledig werden ${ }^{4}$ ).

In der Eigenschaft eines absoluten Rechts von unbeschränktem Umfange hat die Gewalt der adeligen Grundherren Polens über ihre Leibeigenen bis über die Mitte des achtzehnten Jahrhunderts hinaus fortgedauert. Erst ein Gesetz vom Jahre $1768^{5}$ ) war bestimmt, ihrem ius vitae et necis

1) S. oben S. 52. $\left.-{ }^{2}\right)$ Vgl. 1. 16, $\$ 3$ D. qui et a quib. $(40,9)$, 1. 2. 3 C. de long. temp. praescript. $(7,22)$. $\left.-{ }^{3}\right)$ S. Hanow Note 96 zu seiner Ausgabe des Ius Culmense ex ult. rev. (Dantrici, 1743) I, 8, c. 3. Nach älterem poInischen Recht verjährte das Abforderungsrecht der Herren in Hinsicht der ihnen entlaufenen Bauern mit dem Ablauf von 3 Jahren und 6 Wochen, und bei Kenntniss von dem Aufenthalte des Entwichenen sogar schon in 1 Jahre. S. Hanow a. a. O. und die dort beigebrachten Belege, darunter das oben S. 51, Note 1 citirte Statut Cusimir. III., a. 1347, c. 138 (Bandtkie p. 113-114). - 4) S. Cromer, 1. c. p. 499 . Dresner l. c. p. 60 , Note 7 , p. 62 , Note F. Es war der im Text angegebene, zugleich der einzige Fall, wo man noch an eine Vorschrift des älteren, mehr bauerfreundlichen Rechts anknüpfte, nicht zwar an die Statuten König Kasimir des Grossen, wohl aber an ein Statut des Königs Johann Albert von 1496, c. 14 (Bandtkie p. 343) und an die in die Regierung des Königs Alexander III. fallenden Stat. Procer. von 1503 (s. Leges ct. [ed. Konarski] [I] p. 293, Herbert de Fulstein, Stat. verbo Kmetho p. 237. 238). Man setzte sich dabei sogar über die Beschränkungen hinweg, die sich im älteren Recht vorfanden. Während nämlich König Johann Albert immer nur einem von mehreren Bauersöhnen den freien Abzug gewährt hatte, so wurde dies Recht jetzt allen Bauersōhnen, ja überhaupt allen unfreien Leuten eingeräumt, sofern sie sich mit Erfolg den Studien gewidmet hatten. S. Dresner l. c. p. 62, Note F. - s) Dasselbe findet sich abgedruckt bei 
Schranken $z u$ setzen. Sie sollten fortan nicht mehr für befugt gelten, ihre unfreien Leute willkürlich zu tölten, ohne desshalb einer Criminalstrafe zu verfallen. Im iibrigen behielt es in Ansehung der Leibeigenen des Adels sein Bewenden bei dem Zustande der Rechtlosigkeit, der sie im sechzehnten Jahrhundert anhein gefallen waren ${ }^{1}$ ).

Von ihnen habe ich bisher allein gesprochen.

Wie aber verhielt es sich mit den persönlichen Verhältnissen der unfreien Bauern auf den Gütern der Geistlichkeit und auf den königlichen Domänen?

Hierüber jetzt noch ein paar Worte.

Die unfreien Bauern der Geistlichkeit waren juristisch betrachtet nicht viel besser gestellt als die Leibeigenen des Adels. Es gab kein Gericht, welches über ihre Klage zu entscheiden berufen gewesen wäre. Sie waren so der willkürlichen Behandlung der Gutsverwalter preisgegeben. Immerhin konnten sie sich doch mit Bitten und Beschwerden an die Capitel und geistlichen Oberen als an ihre Grundherrschaften wenden, welche gewöhnlich menschlich verfuhren und sie gegen Vergewaltigung in Schutz nahmen ${ }^{2}$ ). Auch er-

Ostrowski, Givilrecht der polnischen Nation (Berlin, 1797) I, S. 294. Es ward darin ,aufs feyerlichste festgesetzt, dass von jetzt an, sowie ein Edelmann, und ein Bauer für eines Bauern Entleibung mit dem Leben bestraft wird, auch ein Edelmann, der einen Bauern boshafter Weise und nicht durch Zufall, sondern freywillig und mit Bedacht tödtet, nicht ferner mit einer Geldbusse an denjenigen, dessen Unterthan der Entleibte war, sondern mit Strafe des Schwerdtes von dem competenten Gericht bestraft werden soll". S. dazu Ostrowski a. a. O. S. 295.296.

1) Auch jetzt konnte man daher noch sagen, dass ,in Absicht der Behandlung und Loslassung" die Unterthanen des polnischen Adels „beynahe kein besseres Schicksal haben, als die römischen Sklaven"; Worte Ostrowskis a. a. O. I, 12. S. ferner Holsche, Geographie und Statistik von West-, Süd- und Neu-Ostpreussen II, S. 189. Wie der letztere Schriftsteller constatirt, waren selbst noch in der allerletzten Zeit der polnischen Selbständigkeit die Bauern der Edelleute ,wirkliche Sklaven“, welche durch ihre Herren nicht nur von einem auf den anderen $H$ of versetzt, sondern auch verkauft, vertauscht, verschenkt und überhaupt ,ganz wie eine Sache" behandelt werden konnten. 2) Cromer, Polonia in dem Abschnitt de situ Poloniae p. 519 und dazu Holsche a. a. O. II S. 188. 
mangelten sie nicht jeder Vermögens- und Dispositionsfähigkeit. Es stand ihnen daher frei, über ihren Nachlass vor dem geistlichen Richter letztwillig zu verfügen ${ }^{1}$ ).

Weit günstiger war die Lage der Bauern auf den Krongütern. Von der persönlichen Sklaverei befreit, galten sie als partei- und processfähig. Nicht zwar gegen den Fiscus selbst, wohl aber gegen die Starosten als die Inhaber und Nutzniesser der Domänen stand ihnen der Rechtsweg bei den Referendariats- und Assessorialgerichten offen ${ }^{2}$ ). Sonst waren sie gutsbehörige Leute (glebae adscripti). Wenigstens darf man dies annehmen. Es spricht dafür die Geschichte der polnischen Leibeigenschaft. War diese ursprünglich keine Sklaverei, so hatte sie doch die Bedeutung einer Gutsbehörigkeit nicht sowohl bloss in Ansehung der leibeigenen Leute im engeren Sinne (servi), sondern auch der Kmethen. Während auf den Gütern der Edelleute die Leibeigenschaft den Charakter der Sklaverei annahm, welcher gleichmässig Kmethen wie Leibeigene anheimfielen, blieben die unfreien Bauern auf den Krongütern oder Domänen gutsbehörig, wie sie das seither schon gewesen waren. Denn die ältere Gesetzgebung erstreckte sich auf die Bauern des Königs ebensogut, wie auf die der Geistlichkeit und des Adels. Es wurde mit ihnen nach denselben Grundsätzen verfahren ${ }^{3}$ ).

Welche Bewandtniss es mit der Leibeigenschaft im eigentlichen Polen hatte, von dem ein Theil mit dem sog. Netzdistrict 1772 an Preussen kam, wissen wir nunmehr.

Wie aber sah es damit in Westpreussen aus während der Zeit, wo dieses Land nach dem Thorner Frieden von 1466 in Realunion mit Polen stand?

(Schluss folgt.)

1) S. Herbertus de Fulstein, Chronic. p. 454. - 2) Holsche a. a. O. S. $157 . ~-{ }^{3}$ ) Stat. Casimir. III., a. 1347 , c. 138 oben S. 51, Note 1. Stat. Ioann. Albert. a. 1496, c. XIV (Bandtkie p. 343): „Istud quoque statutum decernimus ad bona mensae nostrae regalis, ac spiritualium, et saecularium personarum, nullis exceptis." Stat. Sigismundi I. Bydgostiae a. 1520 promulgat. De laborib. kmethon. (Leges ct. [ed. Konarski] [I] p. 394. Herbert. de Fulstein, Stat. verbo kmetho p. 233. 234. 